\title{
Neonatal consumption of oligosaccharides deeply increases L-cells density without any significant consequence on adult eating behavior
}

\author{
Gwenola Le Dréan ${ }^{1,2,3, *}$, Anne-Lise Pocheron ${ }^{1,2,3}$, Hélène Billard ${ }^{1,2,3}$, Isabelle Grit ${ }^{1,2,3}$, Anthony Pagniez ${ }^{1,2,}$ \\ , Patricia Parnet 1, 2, 3 , Éric Chappuis ${ }^{4}$, Malvyne Rolli-Derkinderen ${ }^{2,3, ' 5}$ and Catherine Michel \\ 1 NUN, INRA, CHU Nantes, UMR1280 PhAN, F-44000 Nantes, France ;gwenola.ledrean@univ-nantes.fr, \\ anne-lise.pocheron@univ-nantes.fr, helene.billard@univ-nantes.fr, isabelle.grit@univ-nantes.fr, \\ anthony.pagniez@univ-nantes.fr, patricia.parnet@univ-nantes.fr,catherine.michel@univ-nantes.fr \\ IMAD, F-44000 Nantes, France \\ 3 CRNH-Ouest, F-44000 Nantes, France \\ 4 Olygose, parc technologique des Rives de l'Oise,F 60280 Venette, France ; eric.chappuis@olygose.fr \\ 5 NUN, INSERM, CHU, UMR 1235 TENS, F-44000 Nantes, France ; malvyne.derkinderen@univ-nantes.fr \\ * Correspondence: gwenola.ledrean@univ-nantes.fr; Tel.: +33-244-768-076
}

\begin{abstract}
:
Oligosaccharides (OS) are commonly added to infant formulae but their physiological impacts, particularly those potentially involved in adult health programming, are poorly described. In adult animals, OS modify microbiota and stimulate colonic fermentation and enteroendocrine cells (EEC) activity. Since neonatal changes in microbiota and/or EEC density could long last and EEC-derived peptides regulate short-term food intake, we hypothesized that neonatal OS consumption could modulate early EEC with possible consequence on adult eating behavior.

Suckling rats were supplemented with FOS, GOS/inulin mix, $\alpha$ GOS $\left(3.2 \mathrm{~g} \mathrm{~kg}^{-1}\right.$ ), or control solution from postnatal days (PND) 5 to 14/15. Pups were either sacrificed at PND14/15 or weaned at PND21 to standard chow. Impacts on both microbiota and EEC were characterized at PND14/15 and eating behavior at adulthood.

Very early OS supplementation drastically impacted intestinal environment, endocrine lineage proliferation/differentiation particularly in the ileum as well as density of GLP-1 cell and production of satiety-related peptides (GLP-1 and PYY) in neonatal period but failed to induce any significant enduring changes in intestinal microbiota, enteropeptides secretion or eating behavior, later in life.

Altogether our results demonstrate no programming effect of OS on satiety peptides secreted by L-cell nor on food consumption, what is reassuring in a human perspective.
\end{abstract}

Keywords: prebiotic, gut-brain, programming, microbiota, L-cell, eating behavior

\section{Introduction}

Preventing unhealthy feeding behaviors is highly desirable since deleterious eating habits are associated with health problems including higher risk of overweight or obesity [Lindsay et al 2017]. Because eating behavior is the result of integrated central and peripheral biological systems that are influenced by genetic, psychologic and environmental factors [MacLean et al., 2017], its optimization is highly complex and requires to fully elucidate the mechanisms that control eating behavior. Indeed, central regulation of appetite is mediated by peripheral inputs generated by stomach distension, signals arising from gut epithelium that senses nutrient availability, such as satiety regulatory peptides synthetized and released by enteroendocrine cells (EEC), as well as long-term energy signals released by adipose tissue and cerebral inputs generated by hedonics and rewards circuits [Schwartz 2000, Berthoud et al, 2006, MacLean et al 2017].

Besides evident progress in understanding these interconnections, recent advances include two major findings: first, eating behavior may be programmed very early in life and second, it could be regulated by intestinal microbiota.

In accordance with the developmental origin of health and disease [DOHaD] theory, adverse early-life conditions may predispose to eating disorders [Gaetani 2106]. Among environmental stressors that may have an action, it is suggested from both animal and human studies that perinatal nutrition could program appetite [see for reviews Cripps et al 2005; Ross and Desai 2014; Parnet et al. 2016]. In rodents, experiments based on maternal nutrition restriction or and/or manipulation of litter size have demonstrated that both pre- and post-natal nutrition may alter food intake [Desai et al. 2007; Orozco-Solis et al 2009., Coupé et al 
2011, Ndjim et al 2017] and/or food preference [Coupé et al 2012, Martin-Agnoux et al 2014; Paradis et al 2017] in offspring, with subsequent repercussions at adulthood. In humans, although controversial results have been observed about the influence of prenatal nutrition on later eating behavior [see for review van Deutekom et al. 2017], some observational evidences suggest that early nutrition/growth affects appetite regulation [Lussana et al 2008; Perala et al., 2012, van Deutekom et al. 2016] and food preference programming as demonstrated after repeated exposition to novel flavors [De Cosmi et al 2017].

With regard to the involvement of intestinal microbiota in feeding behavior, although the ability of intestinal fermentation to stimulate the expression of satiety peptides by EEC has been known for several years [Reimer and McBurney 1996, Kok et al 1998], it is only recently, in connection with the growing appreciation of the role of intestinal microbiota in the regulation of host physiology, that this topic has excited interest [van de Wouw et al. 2017; Lam et al 2017; Fetissov 2017; Glenny et al 2017].

As pointed out in these reviews, some observations objectively support the involvement of the intestinal microbiota in the regulation of feeding behavior. Thus, in ascending order of convincing power, we can quote: i) observed dysbiosis in patients suffering eating disorders [Morita et al 2015], ii) the fact that feeding behavior differs between germ-free and conventional animals [see for reviews Wostmann, 1981 or Smith et al 2007], iii) the capability of microbiota disrupting agents- particularly prebiotic oligosaccharides- to affect feeding behavior [Cani et al., 2005; Maurer et al., 2009] and, iv) the delineation of mechanistic pathways linking microbiota and central and peripheral neuroendocrine systems which are responsible for feeding behavior, what supports the existence of a causative link. For example, one can mention EEC secreting appetite-regulating peptide since they have a large diversity of receptors that allow them to integrate microbial inputs such as the fermentation derived short chain fatty acids, secondary biliary salts or the pathogens associated molecular patterns (See for review van de Wouve et al., 2017; Plovier and Cani, 2017).

Conciliating these two emerging issues related to the regulation of feeding behavior, namely its possible programming by early life and its control by intestinal microbiota, we hypothesized that early microbiota modifications may program adult feeding behavior by acting on the peripheral neuroendocrine systems that control it. Such a programming could stem from either the potential programming of intestinal microbiota [e.g.: Morel et al 2015a] or from early impacts with long lasting consequences. In this last respect, it is worth mentioning the capability of microbiota-modulating agents to affect the hypothalamic expression of neurogenic factor (BDNF) expression at neonatal stage [Williams et al 2016], and the potential programmable character of both EEC [Estienne et al 2010] and vagal sensitivity [Ndjim et al 2017]. In addition, the putative ability of the gut microbiota to modulate the epigenome [see for review Mischke and Plosch, 2013; Lallès et al 2016], as well as the ability of the microbiota [Sudo et al 2004] and of certain prebiotics [Savignac et al 2016; Burokas et al 2017] to modulate some behaviors in adults mice can be invoked, assuming the veracity/transposability of these results in the neonatal period.

To test these hypotheses, we aimed at evaluating the ability of nutritionally induced intestinal microbiota modulations to affect the maturation and functioning of EEC in the neonatal period in suckling rats and to determine whether these impacts could result in alterations in eating behavior and in GI peptides secretion at adulthood. We chose to use indigestible oligosaccharides (OS) to modify intestinal microbiota of neonatal rats for two reasons : first, OS, that are recognized as intensively fermented prebiotics [Macfarlane et al 2008] also operant in neonatal rats [Morel et al 2015a] and infants [see for review Skórka et al 2018], have been shown to stimulate enteroendocrine cells (EEC) proliferation and activity in adults animals [Delzenne et al 2007; Overduin et al 2013]; and second, they represent relevant nutrients of neonatal nutrition since they are commonly added to infant formulae to better mimic maternal milk [Sabater et al 2016].

\section{Materials and Methods}

\section{Ethics statement}

All experiments were conducted in accordance with the European Union regulations for the care and use of animals for experimental procedures (2010/63/EU). Protocols were approved by the local Committee on the Ethics in Animal Experiments of Pays de la Loire (France) and the French Ministry of Research (APAFIS\#3652-20 16011910192893 v3). Animal facility is registered by the French Veterinary Department as A44276.

\section{Animals}

Primipare female Sprague-Dawley rats $(n=16)$ were obtained at one-day of gestation (G1) from Janvier-labs (le Genest Saint Isle, France) and housed individually ( $22 \pm 2^{\circ} \mathrm{C}, 12: 12$-h light/dark cycle) with free access to water and chow (A03, Safe Diet, Augy, France). At birth, 8 litters were culled to 8 male pups per mother with systematic cross fostering as previously described [Morel et al., 2015a].

From the 5 to the $14 / 15^{\text {th }}$ days of life, pups received by oral gavage solutions composed of FOS, GOS/In mix (9:1), aGOS or a mix of monomers that are present in the OS solutions (Table 1). Two pups of each litter received daily one of the 4 solutions. The administered volume was adapted to body weight to reach 3.2 g. $\mathrm{kg}^{-1}$ in order to approximate the dose actually consumed by babies fed with prebiotic enriched formulas, after accounting for both the difference in metabolic rate between rats and humans [Nair \& Jacob, 2016] and the true prebiotic content of infant formula [Sabater et al 2016; Nijman et al 2018].

During lactation period, pups were weighted daily and then 3 time a week until adulthood. At postnatal day (PND) 14 or 15, 4 of the 8 litters were slaughtered by decapitation after induction of deep anesthesia (isoflurane $/ \mathrm{O}_{2}, 5 \mathrm{~L} / \mathrm{min}$ ). Rats from the 4 remaining litters were weaned in individual cages at PND21 onto 
standard chow (A03, Safe Diet, Augy, France) until 124/126d, when they were slaughtered as described above. During the follow-up, food consumption was measured 3 times a week.

Table 1. Composition of solutions administered by gavage to pups from PND 5 to $14 / 15\left(\mathrm{~g} / \mathrm{mL}^{-1}\right)$

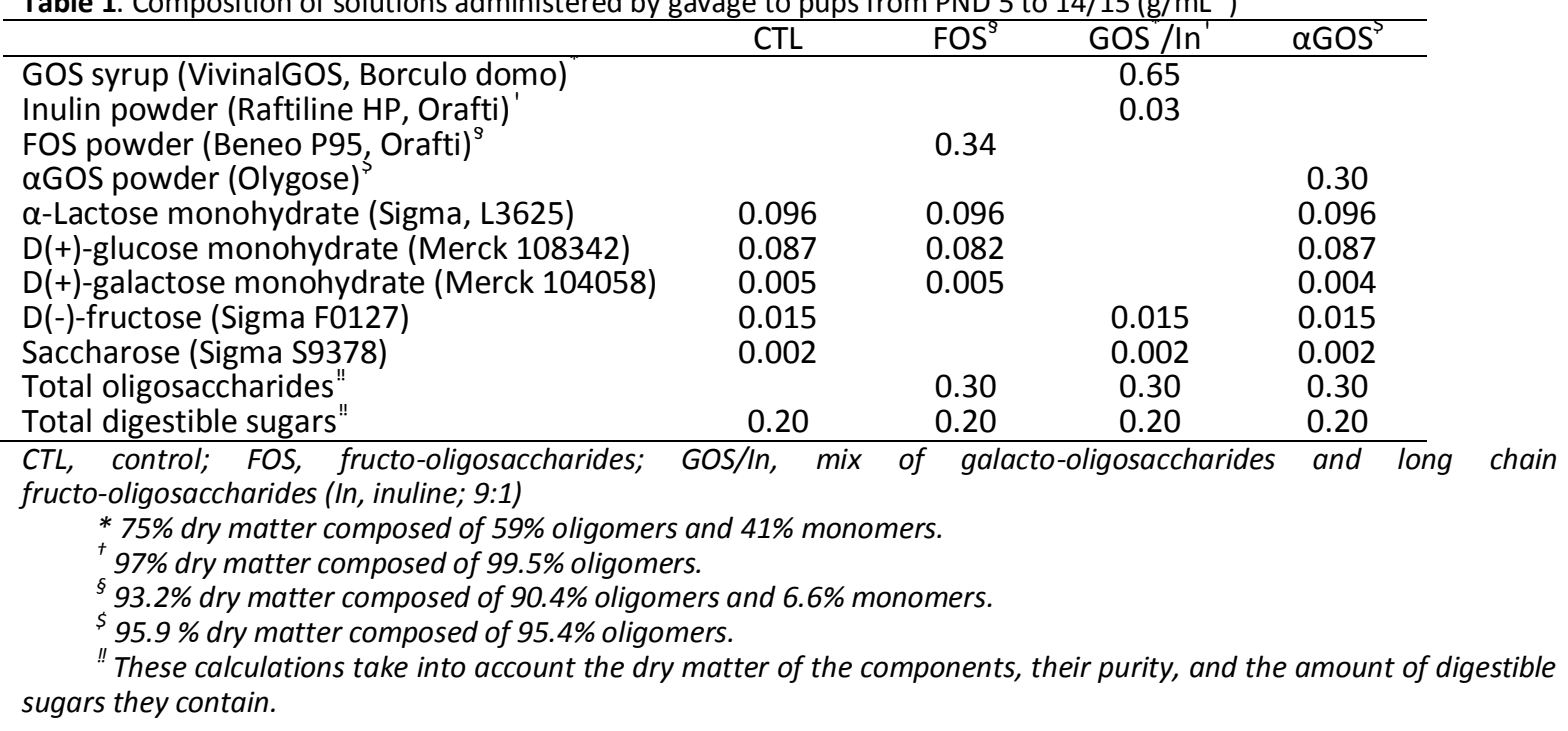

\section{Tissue collection}

Under anesthesia, intracardiac blood was collected in EDTA-containing tube (Microtubes $1.3 \mathrm{~mL} \mathrm{~K} 3 \mathrm{E}$, Sarstedt MG \& Co, Marnay, France) and plasma collected after centrifugation $\left(2000 \mathrm{~g}, 15 \mathrm{~min}, 4^{\circ} \mathrm{C}\right)$ was frozen at $-20^{\circ} \mathrm{C}$ for further analyses. Ileal contents from the most distal $15 \mathrm{~cm}$ were harvested by flushing, using $1 \mathrm{~mL}$ of Hanks' Balanced Salt Solution (HBSS, Thermo Fisher Scientific, St-Herblain, France) and cecocolonic (PND 14/15) or cecal (PND124/126) content was collected, weighted, mixed in 5 or 2 (PND $14 / 15$ and PND124/126, respectively) fold their volume with sterile water. After complete homogeneisation, these cecocolonic/cecal suspensions were centrifuged $\left(7800 \mathrm{~g}, 20 \mathrm{~min}, 4^{\circ} \mathrm{C}\right)$ then both supernatants and pellets were frozen at $-20^{\circ} \mathrm{C}$ for short chain fatty acid (SCFA) and microbiota analyses, respectively. Intestinal tissues (ileum and proximal colon) were rapidly collected and frozen in liquid nitrogen for RNA analysis. Additional tissues samples were fixed in $4 \%$ paraformaldehyde for immunofluorescence analysis.

\section{Eating behavior}

- Meal pattern

Between PND74 and PND99, eating behavior was analyzed in physiological cages (Phecomb cages, Bioseb, Vitrol, France) as previously described [Coupé et al., 2011]. Briefly, rats were housed individually and following $24 \mathrm{~h}$ of acclimatization to the cage, data were recorded from the beginning of the second day (8:00 a.m.) each $5 \mathrm{~s}$ over a 24-h period. Meal parameters extracted from Compulse v1.1.01 software included number of meals, meal size and duration, inter-meal interval, and satiety ratio.

- $\quad$ Taste preference

Preference for sweet taste was measured at PND110 using the bottle test experiment [Silva 1977]. After a $2 \mathrm{~d}$ habituation to the presence of 2 bottles on their own cage, animals had the choice between 2 bottles, one containing tap-water and a second one containing $0.05 \%$ saccharin. For 3 days, drink intake was measured daily. The position of the two bottles was daily inverted to prevent position preference bias. The sweet preference score was calculated as the ratio between the volume of saccharin solution consumed and the total drink intake in $24 \mathrm{~h}$ then multiplied by 100 . A preference is defined if the percentage is superior to 50.

\section{Kinetics of GLP-1 and PPY release and response to glucose}

At PND105, a 4h-kinetics of GLP-1 and PYY release in plasma was performed. Rats were fasted during $16 \mathrm{~h}$ to promote hunger and were refed during $20 \mathrm{~min}$ with a calibrated quantity of chow (A03, safe Diet). Food intake was weighted at the end of the $20 \mathrm{~min}$-period. Blood samples were collected at the tail vein in EDTA-containing tubes (Microvette CB300 EDTA 3K, Sarstedt, Marnay, France) at 0 (15 min before refeeding), 30, 60, 120, and 180 min after the beginning of the meal.

At PND124/126, rats were fasted during $16 \mathrm{~h}$ and $2 \mathrm{~h}$ before sacrifice they received an oral bolus of glucose $\left(2 \mathrm{~kg} / \mathrm{kg}^{-1} \mathrm{BW}\right)$ in order to challenge glucose sensing in GLP-1/PYY-producing EEC.

\section{Plasma gastrointestinal peptides}

Plasma concentration of total GLP-1 and total PYY was assayed by ELISA technique (Millipore EIA kits and Phoenix Pharmaceutical, France, respectively).

\section{Fermentation end-products}

Ileal and cecal supernatants were centrifuged $\left(8000 \mathrm{~g}, 20 \mathrm{~min}, 4^{\circ} \mathrm{C}\right)$, diluted $(1 / 10)$ with oxalic acid 0.5 $\mathrm{M}$ and SCFA (acetate, propionate, butyrate, isobutyrate, valerate and isovalerate) were analysed by gas chromatography as previously described [Fança-Berthon et al., 2010]. 
D- and L- lactate were measured in the supernatants after heating to $80{ }^{\circ} \mathrm{C}$ for $20 \mathrm{~min}$ with Biosentec D/L-lactic acid enzymatic kits according to the manufacturer's instructions (Biosentec, Toulouse, France).

\section{Immunochemistry}

Tissues sections (4-5 $\mu \mathrm{m}$ ) of fixed ileum and proximal colon were double-stained with a goat polyclonal antibody raised against GLP-1 diluted at 1/200 (Santa Cruz Biotechnology, CA, USA) and a rabbit anti-chromograninA (ChrgA, diluted at 1/1000 (Immunostar WI, USA). Anti-goat and anti-rabbit fluorescent secondary antibodies (1/1000) were used to reveal GLP-1 and chromograninA labeling, respectively. Nuclei were counterstained with DAPI. Tissues sections were mounted in Prolong Gold anti-fading medium (Molecular Probes, Thermo Scientific, Courtaboeuf, France). Three sections were analyzed per sample using the Nanozoomer (x20) (Hamamatsu, Japan). Number of fluorescent cells was counted twice by a blind operator, along the crypt-villus axis unit, in 3 different sections, using the NDP view software (Hamamatsu). A total of 40 to 60 crypt-villus units were counted per section.

\section{Quantitative real-time PCR}

Total RNA extraction from ileum and colon was performed using "QIAamp RNA Blood Mini" kit (Qiagen, Courtaboeuf, France) according to manufacturer instructions. Two micrograms RNA were reverse-transcribed using M-MLV reverse transcriptase (Promega, Charbonnières-les-Bains, France). Five microliters of $1 / 40$ dilution of cDNA solution were subjected to RT-qPCR in a Bio-Rad iCycler iQ system (Biorad, Marnes-la-Coquette, France) using the qPCR SYBR Green Eurobiogreen ${ }^{\circledR}$ Mix (Eurobio, Les Ulis, France). Quantitative PCR consisted of 40 cycles, $15 \mathrm{~s}$ at $95^{\circ} \mathrm{C}, 15 \mathrm{~s}$ at $60^{\circ} \mathrm{C}$ and $15 \mathrm{~s}$ at $72^{\circ} \mathrm{C}$ each. Primers sequences are figured in Table S1 in Supplementary Material. For Neurog3 quantification, PrimePCR ${ }^{T M}$ SYBR GreenAssay: Neurog3, rat (Biorad) was used. Relative mRNA quantification was expressed using the $2^{-\Delta \Delta c q}$ method with actin gene as a reference.

\section{Bacterial 16S sequencing of cecal contents}

DNA was extracted from pellets of ceco-colonic contents (max $250 \mathrm{mg}$, using the QIAamp Fast DNA Stool Mini kit (Qiagen, Hilden, Germany) after enzymatic and mechanical disruptions as described previously [Fança-Berthon et al 2010] except that homogenization was carried out at $7800 \mathrm{rpm}$ for 3x $20 \mathrm{~s}$ intervals with $20 \mathrm{~s}$ rest between each interval in a Precellys ${ }^{\circledR}$ "evolution" bead-beater (Bertin, Montigny-le-Bretonneux France). The V4 hyper-variable region of the 16S rDNA gene was amplified from the DNA extracts during the first PCR step using composite primers (5'-CTTTCCCTACACGACGCTCTTCCGATCTGTGYCAGCMGCCGCGGTAA-3' 5'-GGAGTTCAGACGTGTGCTCTTCCGATCTGGACTACHVGGGTWTCTAAT-3') which were based on the primers adapted from Caporaso et al (2011; i.e. 515F and 806R). Amplicons were purified using PP201 PCR Purification Kit (Jena Bioscience, Germany). Paired-end sequencing was performed on a HiSeq 2500 System (Illumina, San Diego, CA, USA) with v3 reagents, producing 250 bp reads per end, according to manufacturer's instructions at the GeT-PlaGe platform (INRA-Toulouse, France). The 16S rDNA raw sequences were analyzed with the FROGS v2 pipeline (http://frogs.toulouse.inra.fr/) [Combes et al 2017; Escudié et al 2018]. After de-multiplexing, quality filtering and chimera removing, the taxonomic assignments were conducted for OTUs with abundance $>0.005 \%$ with Blast using Silva 128 database containing sequences with a pintail score at 80 to determine the bacterial compositions.. FROGSSTAT Phyloseq tools were used to normalize raw abundances by rarefaction and to calculate alpha and beta diversity indices.

\section{Statistical analysis}

Statistical analyses were carried out using GraphPad Prism 6 software (GraphPad Software Inc., San Diego, CA, USA) or R (librairies "stats v3.5.1" and "corrplot v0.84", [R Core Team 2018]). Differences among treatments were searched using one way ANOVA followed by Tukey's multiple comparisons tests for most data with the exception of growth and food consumption data that have been subjected to multiple t-tests with correction for multiple comparisons using the Holm-Sidak method. Sweet taste preference test was analyzed by the one sample t-test to compare values to $50 \%$ (no preference). A p value $<0.05$ was considered statistically significant.

\section{Results}

\subsection{Neonatal OS supplementations did not substantially affect rat growth}

Both FOS and $\alpha$ GOS supplementations were associated with a significant transitory reduction of growth of pups in the early days of the intervention (PND7 to PND10 and PND6 to PND8, respectively, Figure S1). When compared with body weights from the CTL group, these observed differences only reached 9.1 to $11.5 \%$ and did not significantly affect the cumulative weight gains measured either from birth until the end of the supplementation or for the whole lactation period (Table 2). 
Table 2. Bodyweight gain (g) during lactation.

\begin{tabular}{ccc}
\hline Treatment & $\begin{array}{c}\text { BW gain } \\
\text { PND0-14 }\end{array}$ & $\begin{array}{c}\text { BW gain } \\
\text { PND0-20 }\end{array}$ \\
\hline CTL & $30.4 \pm 4.2^{1}$ & $50.5 \pm 6.0$ \\
FOS & $28.0 \pm 3.4$ & $45.7 \pm 4.6$ \\
GOS/In & $29.4 \pm 3.3$ & $49.6 \pm 5.8$ \\
$\alpha G O S$ & $27.9 \pm 2.7$ & $46.8 \pm 5.1$ \\
\hline
\end{tabular}

${ }^{1}$ Data are means \pm SD collected from the total effective of rats ( $n=15-16$ per group). BW, bodyweight.

No significant differences in bodyweight were observed between groups after weaning (Figure S2).

\subsection{Neonatal OS supplementations exerted a marked immediate impact on intestinal environment.}

\subsubsection{OS supplementations modified both composition and activity of neonatal intestinal microbiota}

Following 16S sequencing, no significant differences were noticed in raw sequences numbers between cecocolonic samples collected at PND14/15 (355245 $\pm 10367,30306 \pm 13817,40275 \pm 18343$ and $31808 \pm$ 10101 for CTL, FOS, GOS/In and $\alpha$ GOS, respectively) or in percentages of sequences kept after quality filtering $(83.8 \pm 4.0,76.4 \pm 18.4,83.9 \pm 4.2$, and $81.7 \pm 7.1)$. Cecocolonic contents of the animals supplemented with OS exhibited similar reductions in richness $(p<0.001)$ as compared with the CTL animals (Chao1 values: $66.2 \pm 21.0,72.9 \pm 28.1$, and $73.9 \pm 35.3$ for FOS, GOS/In and $\alpha$ GOS, respectively versus 180.0 \pm 35.7 for $\mathrm{CTL}$ ). The cluster dendrogram generated using weighted UniFrac metric which illustrate beta or between-sample diversity, highlighted an obvious dissimilarity between the microbiotas of the OS-supplemented animals and those of the animals from the CTL group (Figure 1) but did not allow evidencing any effect of the nature of the OS.

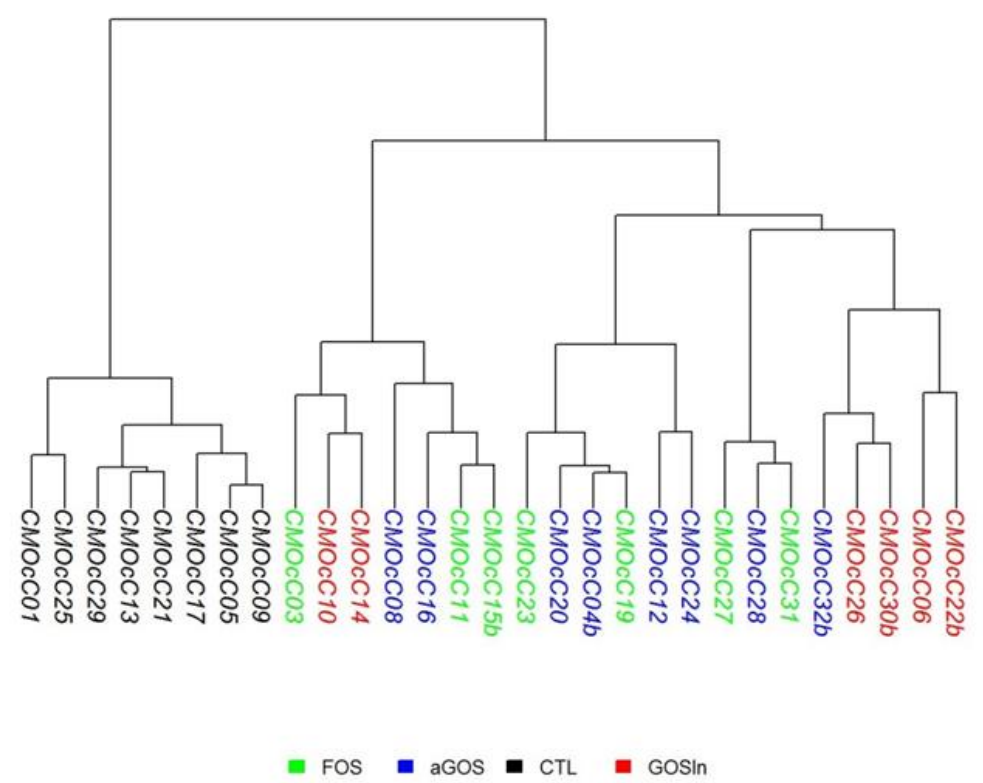

Figure 1. Hierarchical clustering based on the Ward's method of phylogenetically informed distance matrix computed using the weighted UniFrac metric for cecocolonic contents collected at PND 14/15 ( $n=6$ to 8 per group.).

When considering families occurring at more than $0.01 \%$ of the total sample abondances (Table 3 ) OS impact was typified by significant decreases in Lactobacillaceae, Bacteroidales S24-7 group, Prevotellaceae, Streptococcaceae, Peptococcaceae, Coriobacteriaceae, Aerococcaceae, Family XIII, and Rikenellaceae. Moreover, OS supplementation decreased Ruminococcaceae but this impact reached statistical significance for FOS and $\alpha \mathrm{GOS}$ only. These decreases in relative abundances were differently compensated according to the OS: increases in Bifidobacteriaceae reached statistical significance following FOS and $\alpha \mathrm{GOS}$ supplementations, Enterobacteriaceae were increased following aGOS supplementation and Lachnospiraceae were increased following GOS/In supplementation.

Significant differences within OS were scarce and only occurred between GOS/In and $\alpha$ GOS in their impacts on Lachnospiraceae (Table 3). 
Table 3. Relative abundances (\%) for families with abundances $>0.01 \%$ at PND $14 / 15$ according to the postnatal OS supplementation.

\begin{tabular}{|c|c|c|c|c|}
\hline Family & CTL & FOS & GOSIn & $\alpha G O S$ \\
\hline Actinomycetaceae & $0.095 \pm 0.084^{1}$ & $0.028 \pm 0.032$ & $0.076 \pm 0.056$ & $0.068 \pm 0.058$ \\
\hline Aerococcaceae & $0.086 \pm 0.029^{\mathrm{a}}$ & $0.011 \pm 0.011^{b}$ & $0.015 \pm 0.012^{b}$ & $0.020 \pm 0.019^{b}$ \\
\hline Alcaligenaceae & $0.020 \pm 0.041$ & $0.030 \pm 0.047$ & $0.378 \pm 0.576$ & $0.036 \pm 0.053$ \\
\hline Bacteroidaceae & $2.352 \pm 0.991$ & $6.510 \pm 10.047$ & $6.837 \pm 5.729$ & $3.719 \pm 5.492$ \\
\hline Bacteroidales.S24.7.group & $6.812 \pm 2.953^{a}$ & $0.053 \pm 0.080^{b}$ & $0.098 \pm 0.094^{b}$ & $0.084 \pm 0.103^{b}$ \\
\hline Bifidobacteriaceae & $0.624 \pm 0.45^{a}$ & $17.188 \pm 12.735^{b}$ & $7.894 \pm 7.947^{\mathrm{ab}}$ & $13.577 \pm 10.631^{b}$ \\
\hline Campylobacteraceae & $0.009 \pm 0.024$ & $0.093 \pm 0.220$ & $0.066 \pm 0.151$ & $0.294 \pm 0.546$ \\
\hline Clostridiaceae.1 & $0.273 \pm 0.146$ & $2.413 \pm 3.231$ & $5.509 \pm 8.749$ & $5.044 \pm 4.581$ \\
\hline Coriobacteriaceae & $0.108 \pm 0.039^{a}$ & $0.039 \pm 0.034^{b}$ & $0.036 \pm 0.041^{b}$ & $0.023 \pm 0.018^{b}$ \\
\hline Corynebacteriaceae & $0.032 \pm 0.023$ & $0.007 \pm 0.011$ & $0.020 \pm 0.030$ & $0.012 \pm 0.023$ \\
\hline Desulfovibrionaceae & $0.098 \pm 0.182$ & $0.000 \pm 0.000$ & $0.003 \pm 0.008$ & $0.006 \pm 0.014$ \\
\hline Enterobacteriaceae & $13.86 \pm 5.97^{a}$ & $23.48 \pm 12.23^{\mathrm{ab}}$ & $19.51 \pm 6.69^{b}$ & $33.42 \pm 11.99^{b}$ \\
\hline Enterococcaceae & $0.435 \pm 0.707$ & $0.145 \pm 0.203$ & $2.892 \pm 6.293$ & $0.542 \pm 0.771$ \\
\hline Erysipelotrichaceae & $0.682 \pm 0.387$ & $4.080 \pm 3.988$ & $3.774 \pm 4.950$ & $2.766 \pm 3.002$ \\
\hline Family.XIII & $0.062 \pm 0.030^{a}$ & $0.004 \pm 0.008^{b}$ & $0.000 \pm 0.000^{b}$ & $0.001 \pm 0.003^{b}$ \\
\hline Lachnospiraceae & $6.327 \pm 2.300^{a}$ & $9.787 \pm 6.180^{\mathrm{ab}}$ & $15.298 \pm 9.544^{b}$ & $4.962 \pm 4.587^{b}$ \\
\hline Lactobacillaceae & $57.47 \pm 8.72^{a}$ & $28.74 \pm 10.84^{b}$ & $24.47 \pm 5.71^{b}$ & $31.13 \pm 11.24^{b}$ \\
\hline Micrococcaceae & $0.140 \pm 0.064$ & $0.075 \pm 0.074$ & $0.071 \pm 0.053$ & $0.110 \pm 0.105$ \\
\hline Pasteurellaceae & $0.582 \pm 0.581$ & $0.236 \pm 0.235$ & $0.456 \pm 0.297$ & $0.394 \pm 0.446$ \\
\hline Peptococcaceae & $0.396 \pm 0.182^{a}$ & $0.006 \pm 0.015^{b}$ & $0.015 \pm 0.019^{b}$ & $0.007 \pm 0.021^{b}$ \\
\hline Peptostreptococcaceae & $0.747 \pm 0.485$ & $0.471 \pm 0.262$ & $0.543 \pm 0.108$ & $0.640 \pm 0.379$ \\
\hline Porphyromonadaceae & $1.242 \pm 1.153$ & $5.924 \pm 9.747$ & $9.826 \pm 15.228$ & $2.055 \pm 5.475$ \\
\hline Prevotellaceae & $2.136 \pm 1.540^{a}$ & $0.014 \pm 0.016^{b}$ & $0.011 \pm 0.018^{b}$ & $0.028 \pm 0.060^{b}$ \\
\hline Rikenellaceae & $0.034 \pm 0.039^{a}$ & $0.001 \pm 0.004^{b}$ & $0.000 \pm 0.000^{b}$ & $0.001 \pm 0.003^{b}$ \\
\hline Ruminococcaceae & $3.242 \pm 0.743^{a}$ & $0.135 \pm 0.147^{b}$ & $1.610 \pm 2.622^{b}$ & $0.406 \pm 0.665^{b}$ \\
\hline Streptococcaceae & $2.118 \pm 0.620^{a}$ & $0.510 \pm 0.316^{b}$ & $0.586 \pm 0.156^{b}$ & $0.643 \pm 0.450^{b}$ \\
\hline
\end{tabular}

In agreement with these compositional changes, the 10 days supplementation deeply affected fermentation end-products concentrations in both ileal and colonic contents at PND14/15.

In the ileum, lactate concentration was below the detection limit $(0.22 \mathrm{mM})$ in all animals and the concentration of acetate, the sole SCFA present at this age in this intestinal segment, was significantly increased $(p<0.005)$ by FOS supplementation $(6.9 \pm 3.6 \mathrm{mM})$ as compared with CTL $(0.3 \pm 0.4 \mathrm{mM}), \mathrm{GOS} / \mathrm{In}$ $(1.6 \pm 2.0 \mathrm{mM})$ and $\alpha \mathrm{GOS}(0.6 \pm 0.8 \mathrm{mM})$.

In the cecum, the concentration of total end-products was increased in all OS groups as compared with CTL (Figure 2) This was mainly due to an increase in SCFA concentration, which reached statistical significance only with FOS and also, for $\alpha$ GOS only, to an increase in lactate concentration. 

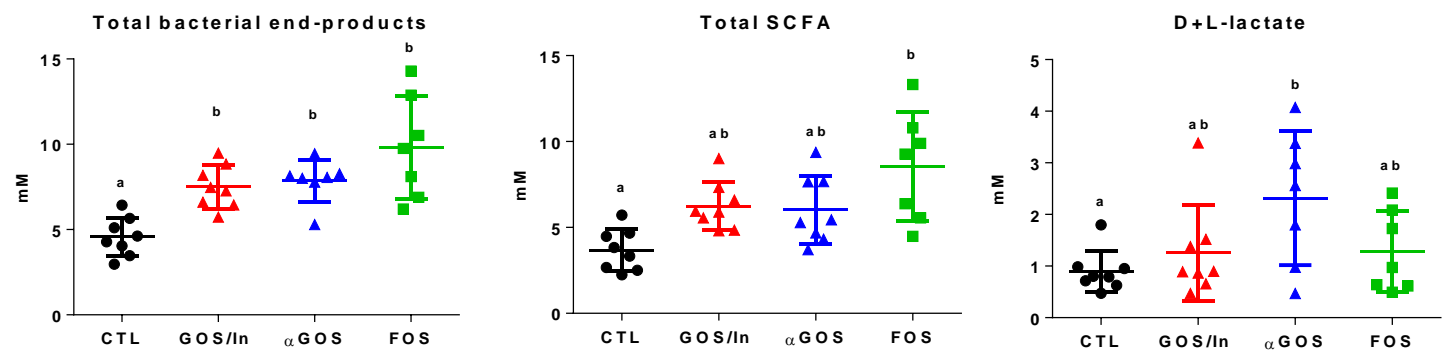

Figure 2. Cecocolonic concentrations of fermentation end-products. Individual, mean and SD values are plotted ( $n=$ 7 to 8 per group). Different letters indicated significant difference $(p<0.05)$ between groups.

Increases in total SCFA reflected acetate ones which were significantly increased by both FOS and GOS/In and were paralleled by significant decreases of $\mathrm{pH}$ values (Table 3). Moreover, OS supplementation shifted microbiotal activity as illustrated by significant changes in the relative proportions of acetate (93. 8 $\pm 4.6,93.1 \pm 4.1$, and $95.4 \pm$ $2.9 \%$ for FOS, GOS/In and $\alpha \mathrm{GOS}$, respectively versus $86.3 \pm 4.5 \%$ for $\mathrm{CTL})$ and propionate $(5.4 \pm 4.6,5.2 \pm 3.4$, and $3.6 \pm 2.9 \%$ for FOS, GOS/In and $\alpha \mathrm{GOS}$, respectively versus $10.7 \pm 3.0 \%$ for $\mathrm{CTL})$. Concentration and relative proportion of butyrate - which is scarcely produced in neonatal stage - were not significantly affected by supplementations.

Table 4. Concentration (mM) of major SCFA in cecocolonic contents at PND 14/15.

\begin{tabular}{ccccc}
\hline Treatment & Acetate & Propionate & Butyrate & pH \\
\hline CTL & $3.17 \pm 1.05^{\mathrm{a}}$ & $0.39 \pm 0.16$ & $0.07 \pm 0.04$ & $6.9 \pm 0.3^{\mathrm{a}}$ \\
GOS/In & $5.82 \pm 1.32^{\mathrm{D}}$ & $0.33 \pm 0.21$ & $0.10 \pm 0.09$ & $6.3 \pm 0.2^{\mathrm{D}}$ \\
$\alpha \mathrm{GOS}$ & $5.69 \pm 1.77^{\mathrm{aD}}$ & $0.28 \pm 0.27$ & $0.05 \pm 0.00$ & $6.1 \pm 0.2^{\mathrm{D}}$ \\
FOS & $8.00 \pm 2.94^{\mathrm{D}}$ & $0.47 \pm 0.37$ & $0.06 \pm 0.04$ & $6.2 \pm 0.2^{\mathrm{D}}$ \\
\hline
\end{tabular}

${ }^{1}$ Data are means \pm SD ( $n=7$ to 8 per group). Within columns, values followed by different letters differ significantly at $\mathrm{p}<0.05$.

\subsubsection{OS supplementations modified both differentiation and activity of the neonatal EEC}

In the ileum, a profound effect on the enteroendocrine lineage was induced by the neonatal OS supplementations as revealed by a significant decrease in Neurog3 expression in the OS groups when compared with CTL, whereas early expressed marker in the commitment secretory lineage (Atoh1) was not significantly affected (Figure 3). Relative expression of genes specifically implied in the differentiation of EEC (Pax4 and Pax6) was significantly decreased in OS supplemented groups as compared with CTL whereas expression of Foxa1 did not vary between groups. Similarly to Pax4 and Pax6, Neurod1 expression was reduced in OS groups as compared with CTL but this did not reach statistical significance for FOS. With regard to expression of genes coding for peptides produced by mature L-cells, Pyy was significantly increased in OS groups as compared with CTL. Meanwhile, despite a 2 fold increase in Gcg expression in OS groups compared with CTL, this effect was not statistically significant due to a great variability of expression between samples. 

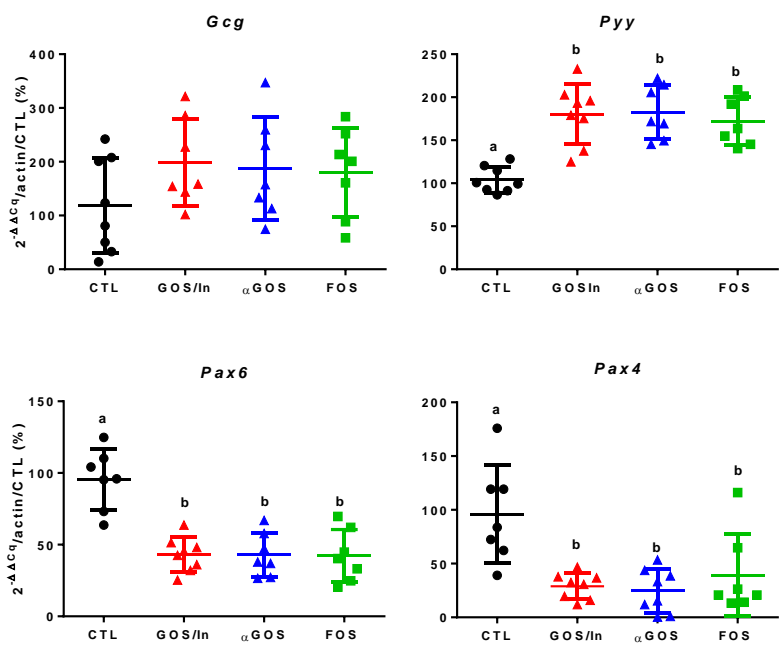

Neurod1

Foxa1
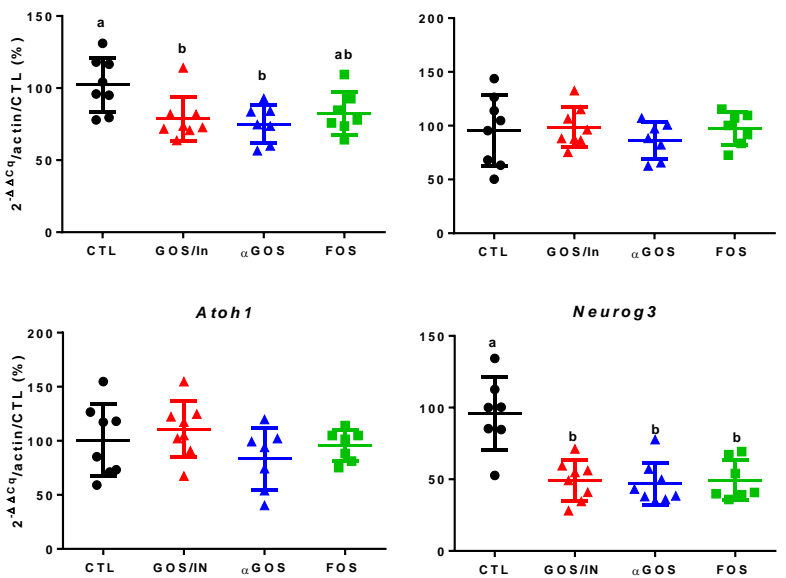

Figure 3. Relative expression of gene implied in the endocrine lineage and in L-cells differentiation in the ileum. Different letters indicate significant difference between groups $(p<0.05)$. Data are fold-change expressed in $\%$ of CTL group. Individual, mean and SD values are plotted ( $n=7$ to 8 per group).

In the proximal colon, the impact of OS supplementations was much more moderated and their only significant effect was a decrease in the expression of Pax4 (Figure S3).

Concomitantly with this profound remodeling in the expression of markers of L-cells differentiation, the number of GLP-1/ChgrA positive cells, i.e. mature EEC, was higher in the ileum of pups from OS groups as compared with CTL but this reached statistical significance for villi only (Figure 4).

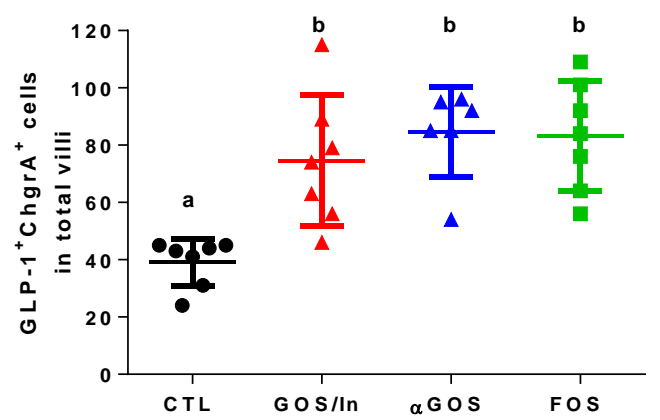

B

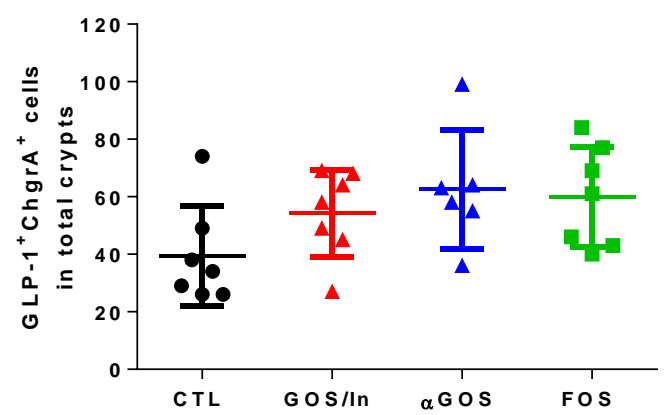

Figure 4. Effect of OS supplementation on the density of GLP-1 cells in ileum: (A) in villi (B) in crypts. Different letters indicate significant differences among groups $(p<0.05)$; Individual, mean and SD values are plotted ( $n=6$ to 7 per group). 
In agreement with this rise in the number of mature EEC, plasma concentrations of GLP-1 (Figure 5A) and PYY (Figure 5B) were significantly increased by all the neonatal OS supplementations, as compared with CTL

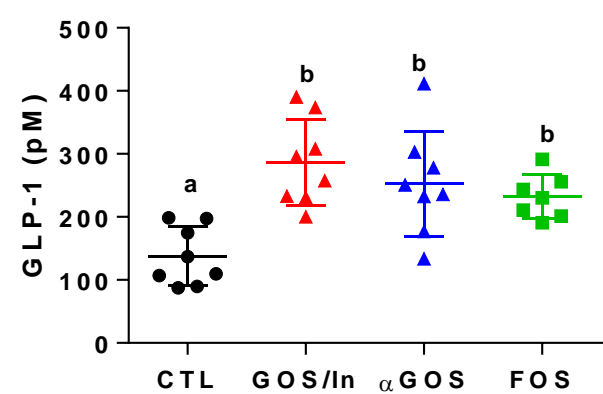

B

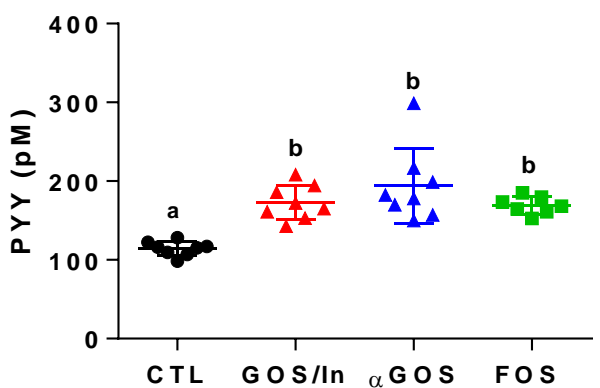

Figure 5. Plasma concentration of (A) Total GLP-1; (B) Total PYY at PND 14/15. Different letters indicate significant differences among groups $(p<0.05)$. Individual, mean and SD values are plotted ( $n=7$ to 8 per group).

Significant positive associations between plasma concentrations of GLP-1 and PYY and the ileal expressions of their respective genes were evidenced (Figure 6A). Conversely, these plasma concentrations as well as the densities of GLP-1 secreting cells were inversely correlated with expressions of Neurog3, Neurod1, Pax4, and Pax6. With respect to associations between microbiota and EEC descriptors (Figure 6B), only some of the differentiating factors (Pax4, Neurod1, Pax6 and Neurog3) exhibited significant positive correlations with the abundances of some bacterial families that correspond to those whose abundance was significantly reduced by OS, except for Prevotellaceae. For these factors, the sole negative correlation was that between Neurod1 and abundance of Clostridiaceae.1. Conversely, PYY and GLP-1 plasmatic concentrations, EEC densities and Pyy expression, but not Gcg expression, were negatively correlated with the same families including Prevotellaceae.

Altogether, these results indicate that OS supplementations profoundly modulate the neonatal microbiota, both in its composition and fermentative activity with repercussions not only in the cecocolon but also, as exemplified with FOS, in the ileum. Increased density of ileal L-EEC and their secreted anorectic hormones, GLP-1 and PYY were observed and concomitantly but unexpectedly, expression of transcription factors beyond the stage of secretory cell engagement (Atoh1) was inhibited. Whether this strong impact of early OS supplementation on satiety peptides-related EEC could last later in life and affect eating behavior has been further investigated. 


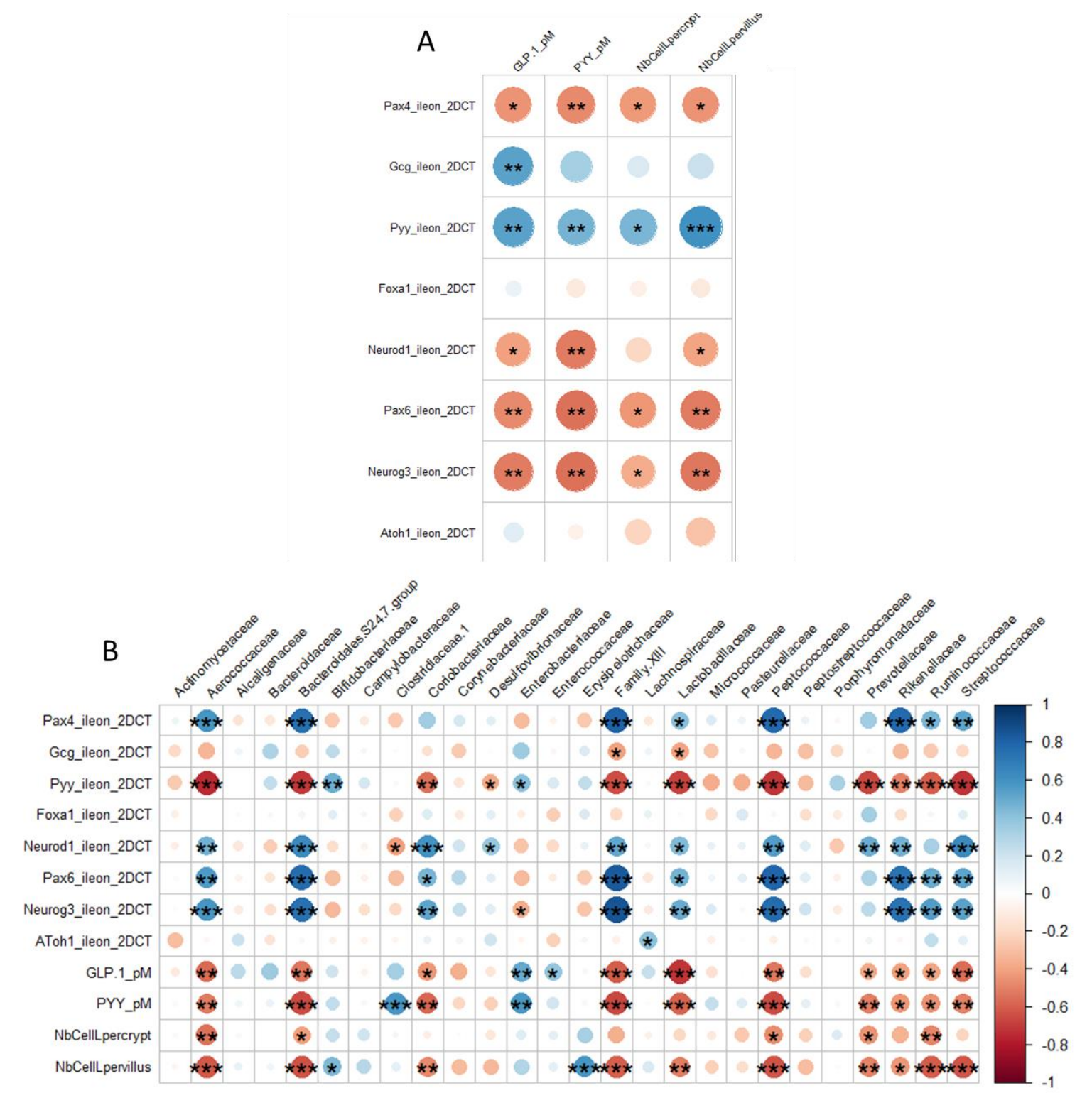

Figure 6. Correlograms within EEC descriptors (A) or between these descriptors and the relative abundances of main bacterial families (B). Positive correlations are displayed in blue and negative correlations in red. The intensity of the color and the size of the circles are proportional to the correlation coefficients. Asterisks indicate the level of significance $(*, p<0.05 ; * *, p<0.01 ; * *, p<0.001)$. On the right of the correlogram, the color legend shows the correspondence between correlation coefficients and colors.

\subsection{Neonatal OS supplementations had no significant long-term consequences}

3.3.1. Neonatal OS supplementations did not significantly program enteropeptides production or eating behavior in adulthood

To investigate the long-term effect of a neonatal supplementation of OS on nutrient sensing in EEC, once pups reached adulthood, we studied the release of GLP-1 and PYY in response to both a 20 min- test meal (PND 74/76) and an oral bolus of glucose (PND 124/126) after a 16h-fasting.

No significant differences were observed between groups in the amount of food consumed during the 20 min test meal (data not shown). In response to this meal, plasma concentration of GLP-1 increased immediately after refeeding and returned to pre-prandial level between 120 and 180 minutes later (Figure 7A). Total amount of secreted GLP_1 during that period, quantified by AUC, did not significantly differ between groups (Figure 7B). PYY secretion did not show any postprandial peak or significant differences between groups (data not shown). 


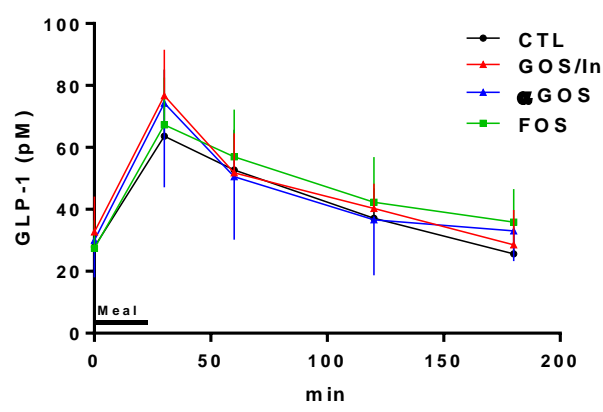

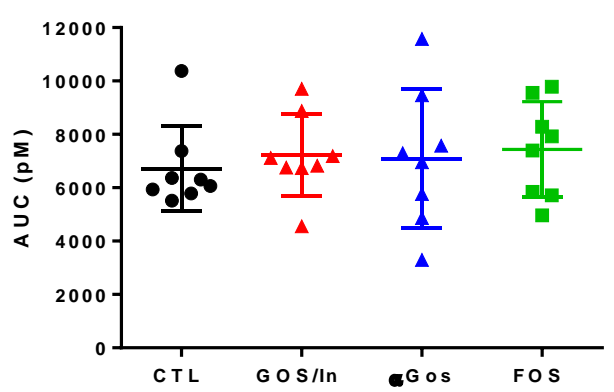

Figure 7. GLP-1 secretion in response to a 20 min-meal. (A) Plasma concentration of total GLP-1 measured during the 3h-kinetic follow-up (means \pm SD); (B) Total amount of GLP-1 secreted during the $0-180$ min period expressed as AUC. Individuals, means and SD are plotted. ( $n=7$ to 8 per groups in $A$ and $B$ ).

Similarly, at PND 124/126, plasma concentrations of GLP-1 (CTL: $34.4 \pm 13.5$; GOS/In: $38.6 \pm 28.6$; $\alpha$ GOS: 28.9 \pm 10.0 and FOS: $37.9 \pm 20.6 \mathrm{pM}$ ) and PYY (CTL: $84.7 \pm 4.0 ; \mathrm{GOS} / \mathrm{In}: 88.7 \pm 7.8 ; \alpha G O S: 91.4 \pm 7.3$ and FOS: 91.5 $\pm 5.8 \mathrm{pM}$ ) measured $2 \mathrm{~h}$ after an oral bolus of glucose did not show any significant difference between groups.

To investigate the long-term effect of a neonatal supplementation of OS on later eating behavior, we followed up the food consumption from weaning to adulthood, performed a refined analyze of feeding pattern using physiological cages from PND75 to PND100 and assessed preference for the sugar taste between PND109 and PND111.

The analysis of food consumption during development only revealed a single significant difference which occurred at PND32 between animals from the FOS and the CTL groups (Figure 8), what indicate that neonatal supplementation with OS did not significantly program the subsequent food intake in our experimental conditions.

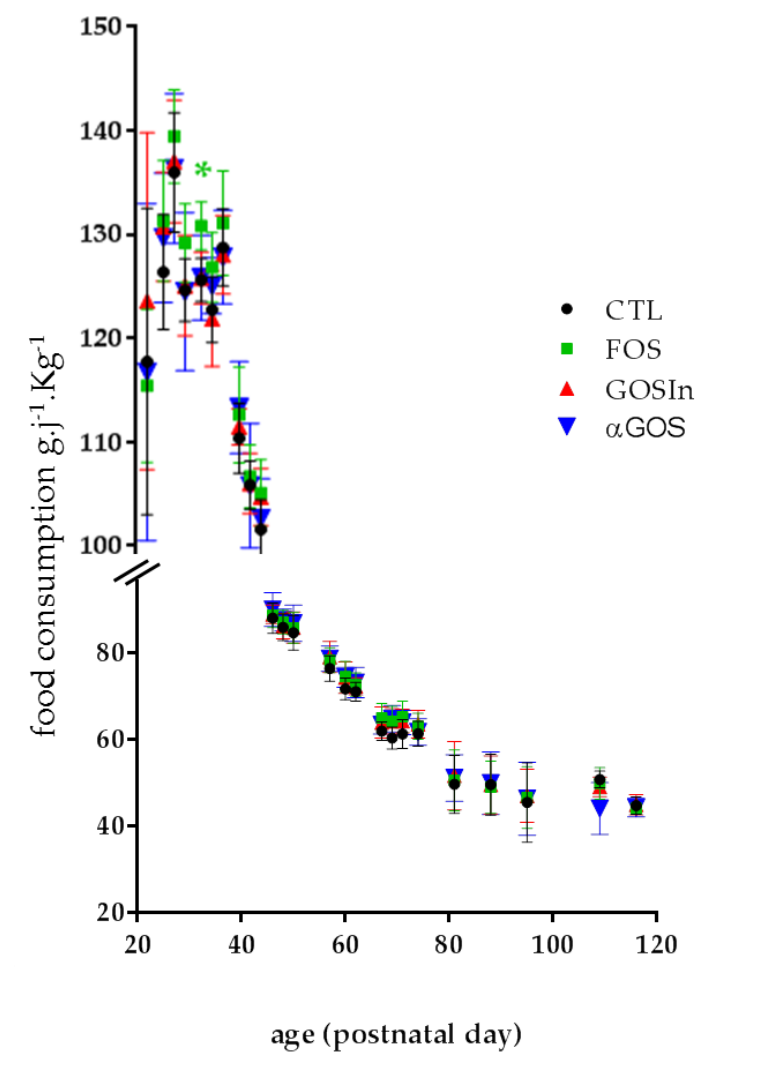

Figure 8. Daily consumption of food during post-weaning. The asterisk indicates a significant difference between FOS and CTL groups $(p<0.05)$. Data are means \pm SD ( $n=7$ to 8 by group and day). 
A

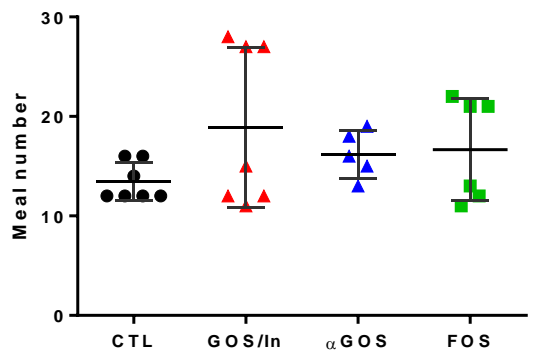

Diurnal period

(8h)

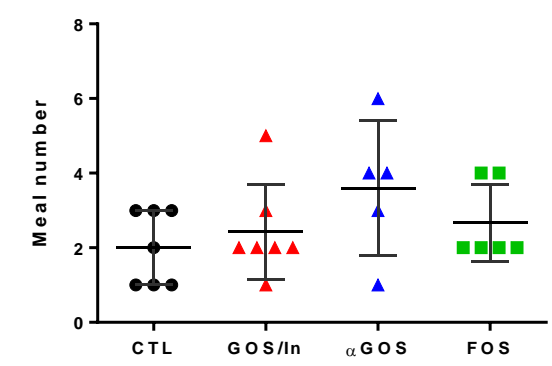

Nocturnal period (12h)

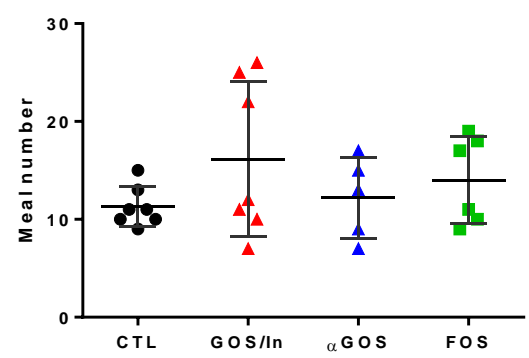

B
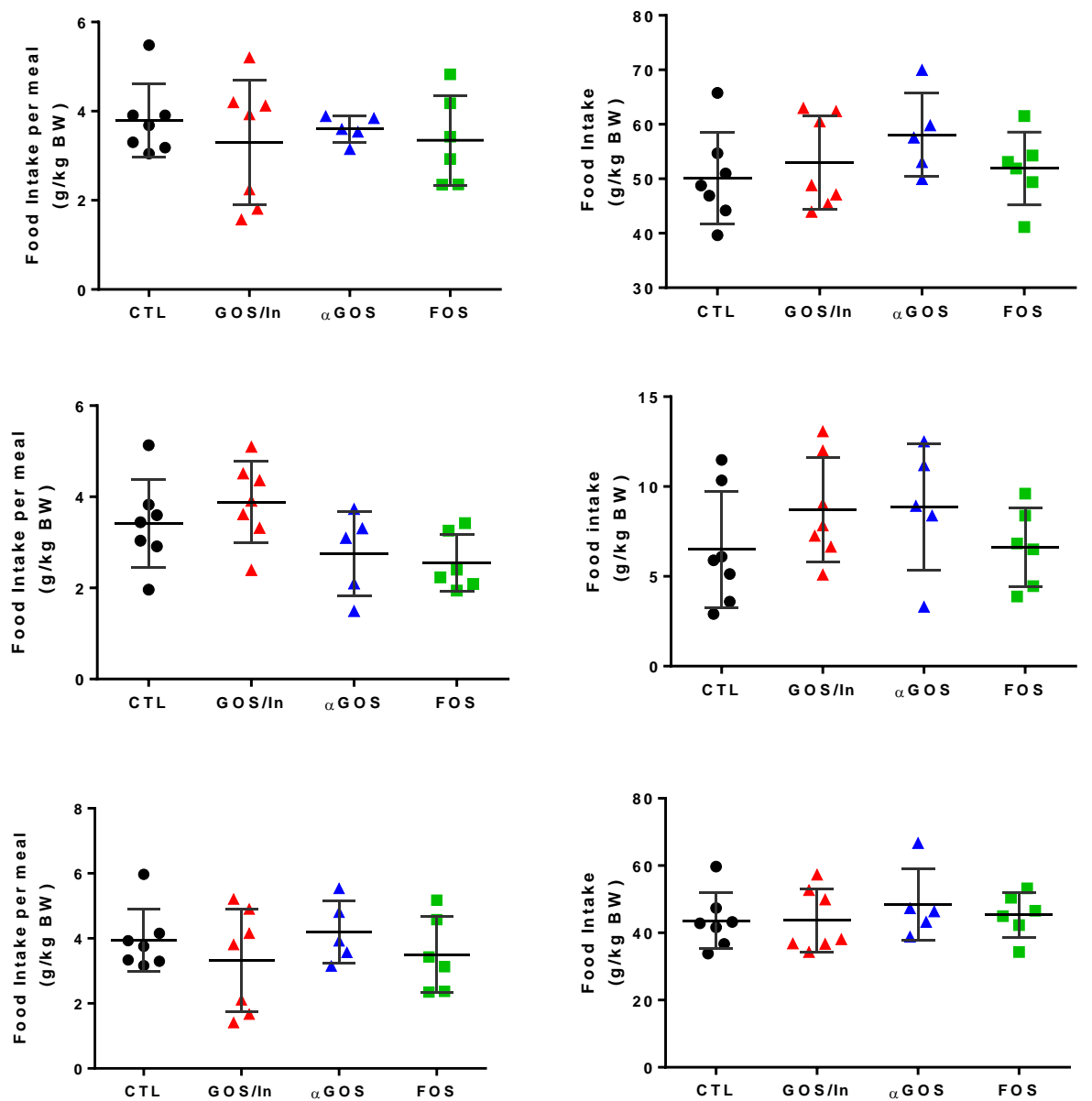

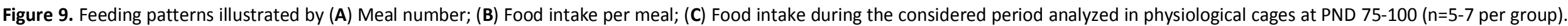

BW, bodyweight. Individuals, means and SD are plotted ( $n=5$ to 8 per groups). 
This lack of effect on daily food consumption was confirmed by the detailed analysis of food consumption: we observed no significant difference in meal patterns among groups, whatever the period of measurement (total $20 \mathrm{~h}$ period of measurement, diurnal period (8h) or nocturnal period (12h) (Figure 9).

During sweet taste preference test, there was no significant difference between groups with regard to the consumption of saccharin solution expressed as percentage of daily drink whatever the test day considered (Figure 10). Strikingly, the preference for sweet test for the GOS/In group did not reach statistical significance on the first test day, in contrast to FOS and $\alpha$ GOS groups. However, this preference did not persist on day 2, conversely to what was observed for the CTL group. This thus suggests that neonatal supplementation of OS slightly reduced the duration for sweet preference at adulthood.

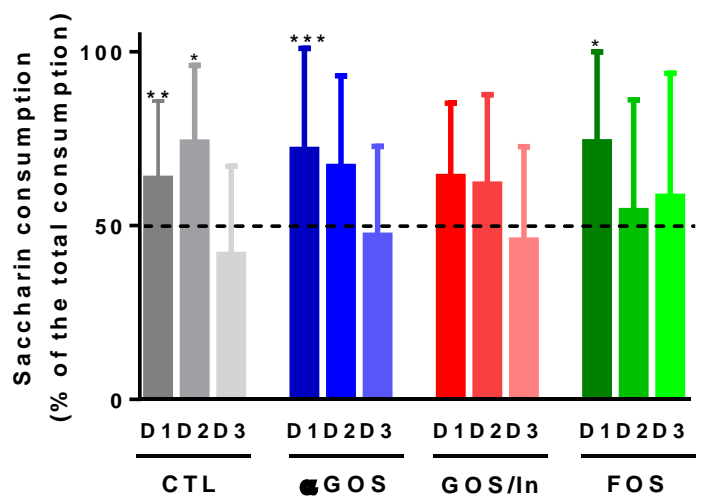

Figure 10. Preference for sweet taste. Data are means $\pm S D(n=7$ to 8$)$. Asterisks represent significant preference as compared with no preference (i.e. $50 \%$, dotted line): ${ }^{*}, p<0.05 ;{ }^{* *}, p<0.01 ;{ }^{* *}, p<0.001$.

\subsubsection{Neonatal OS supplementations did not significantly program adult intestinal microbiota}

At adult age (PND 124/126), no significant differences were observed between treatments with respect to raw number of sequences obtained, percentages of sequences kept after quality filtering, or alpha-diversity indexes (data not shown). Similarly, $\beta$-diversity analysis, principal component analysis on OTUs abundances (Figure S4) as well as comparisons of the cumulated relative abundances at the family level (Figure 11) failed to show any significant difference between cecocolonic samples according to the neonatal supplementation. Finally, neither ileal nor cecocolonic concentrations of SCFA showed significant differences between experimental groups (Table S2).

Altogether, these data did not support any programming impact of neonatal OS supplementation on adult microbiota.

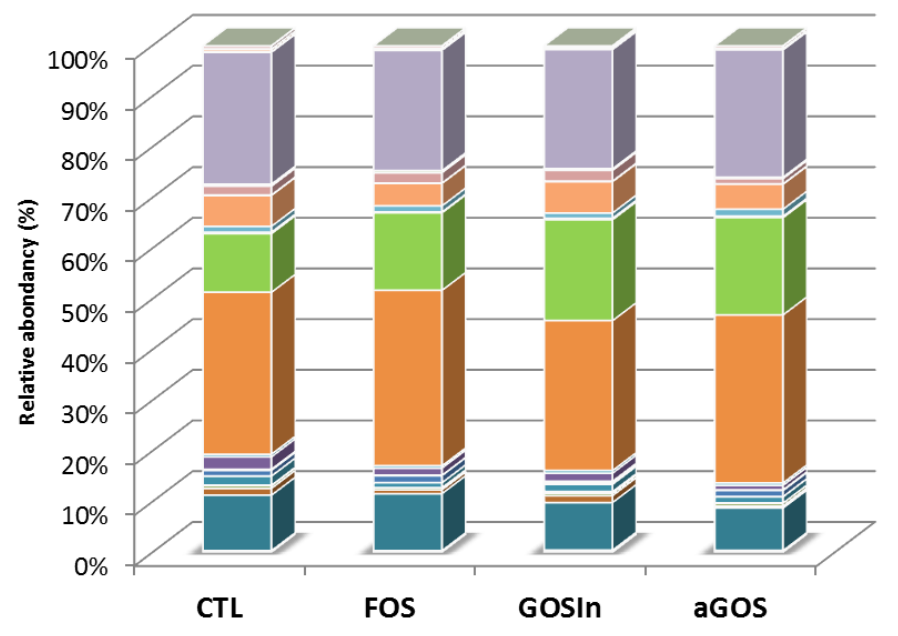

Figure 11. Impact of postnatal OS-supplementation on cecocolonic microbiota composition at PND124/126: families distribution expressed as averaged cumulated relative abundances ( $n=7$ to 8 per group).

\begin{tabular}{|c|c|}
\hline Verrucomicrobiaceae & = unknown family \\
\hline E Leuconostocaceae & EStreptococcaceae \\
\hline W Staphylococcaceae & \# Ruminococcaceae \\
\hline = Rikenellaceae & = Prevotellaceae \\
\hline = Porphyromonadaceae & = Peptostreptococcaceae \\
\hline = Peptococcaceae & = Pasteurellaceae \\
\hline = Multi-affiliation & Micrococcaceae \\
\hline = Lactobacillaceae & Wachnospiraceae \\
\hline = Family XIII & Erysipelotrichaceae \\
\hline Enterococcaceae & Enterobacteriaceae \\
\hline = Desulfovibrionaceae & = Corynebacteriaceae \\
\hline Coriobacteriaceae & E Clostridiaceae 1 \\
\hline = Christensenellaceae & - Carnobacteriaceae \\
\hline = Campylobacteraceae & = Bifidobacteriaceae \\
\hline - Bacteroidales S24-7 group & - Bacteroidaceae \\
\hline Alcaligenaceae & Aerococcaceae \\
\hline Actinomycetaceae & \\
\hline
\end{tabular}

(1)




\section{Discussion}

Considering that regulation of feeding behavior, could possibly be programmed by early life and controlled by intestinal microbiota, we hypothesized that neonatal microbiota modifications may program adult feeding behavior. We thus assessed the ability of nutritionally-induced intestinal microbiota modulations to affect the maturation and functioning of L-EEC in suckling rats and to result in delayed alterations in eating behavior and in GI peptides secretion at adulthood. In this study, we show that neonatal supplementation with 3 different OS strongly impacts cecocolonic microbiota, GLP-1 cells density in the ileum, and production of satiety related peptides in neonatal period, but fails to induce any significant enduring effects at adulthood neither on eating behavior nor gut peptides.

\section{Neonatal OS supplements affected intestinal microbiota despite its immaturity}

Corroborating our previous findings based on a non-exhaustive analysis of the microbiota [Morel et al 2015a], and in agreement with several in vivo and in vitro studies investigating, at adulthood, in humans and animals [see for review Rastall 2010 or e.g.: Liu et al 2017; Wang et al 2017] or in human infants [see for review Skórka et al 2018], the impact of OS (including that of the $\alpha$ GOS [Fehlbaum et al 2018] on intestinal microbiota, all the oligosaccharides used here dramatically affected neonatal microbiota in rat pups. This confirms that the prebiotic property demonstrated in adult rats operates in neonatal pups as well despite the immaturity of the microbiota at this stage of development [Fança-Berthon et al 2010].

Beyond these changes in composition and a reduction in microbiota richness, our neonatal OS supplementations have also modified the activity of the microbiota by stimulating the production of acetate and lactate at the expense of that of propionate. This result stands out from what is observed in adult rats where GOS and FOS are frequently reported as stimulatory for propionate and/or butyrate production [e.g.: Le Blay et al 1999; Overduin et al, 2013]. Such a contradiction probably results from the progressive maturation of the microbiotal capacity to synthesis the different SCFA [Midtvedt \& Midtvedt, 1992]. Thus, the production of butyrate is practically undetectable before the 16th day of life in rat [Fança-Berthon et al 2010]. Anyway, the neonatal OS supplementations we performed resulted in microbiotas that markedly differ from that of unsupplemented animals, what was a prerequisite for investigating the ability of neonatal microbiota modulation to program adult eating behavior or gut peptides response.

\section{OS supplements would stimulate ileal EEC to produce GLP-1/PYY while acting in feedback on endocrine precursors}

Our results showed that neonatal OS supplementation had immediate effects on ileal mature GLP-1-cells by increasing their density in villi and the mRNA expression of Gcg and PYY leading to enhanced plasma concentrations of these two anorectic peptides. These new observations in neonatal rats are consistent with those reported in adult rats for FOS and GOS/In [Cani et al 2004; Cani et al, 2007; Parnell \& Reimer 2012; Delzenne et al 2007, Overduin et al 2013] and are, to our knowledge, reported here for the first time for aGOS. In one of these previous studies, this increased production of GLP-1 was related to higher differentiation of Neurog3-expressing EEC progenitor into L-cells in colon [Cani et al, 2007]. Here, we demonstrated a drastic downregulation of endocrine lineage-devoted genes during OS supplementation, mainly in the ileum. This unexpected result is somewhat complicated to conciliate with an effect of OS on endocrine early precursor leading to produce more L-cell subtype.

Neurog3 marks the endocrine progenitor and is essential for generating newly formed EEC [Li et al., 2011]. Post-neurog3 differentiation and maturation of EEC is controlled by dynamics in transcriptional factors such Neurod1, Pax4 and Pax6 and many others (Arx, Pdx1, Foxa1 and Foxa2). The hierarchy of these events is still poorly understood [Schnonhoff et al, 2004; Beucher et al, 2012, Engelstoft et al, 2013] and the extrinsic factors that may interplay remain largely unknown. In the present study, the well-known effect of OS prebiotics to stimulate L-cells cannot be simply related to an impact on endocrine precursors as suggested in the previously mentioned study [Cani et al, 2007]. As we know that Neurog3 expression is restricted to immature proliferative cells, the decreased Neurog3 expression we observed in ileum may rather reflect a feedback regulation to limit new EEC generation in response to OS supplementation. A similar observation (decrease in duodenal Neurog3 and increased density of EEC) was reported in a model of maternal deprivation [Estienne et al., 2010]. These data and ours suggest that the postnatal environment impact differentiating EEC precursors and not proliferative progenitor, to increase EEC density. High level of circulating GLP-1 has been previously related to increased number of ileal L-cells in Gcgr-deleted mice and this effect involved up-regulation of post-neurog3 transcription factors, affecting proliferation of L-cells precursors [Grigoryan et al., 2012]. Here, expression of these factors namely Neurod1, Pax4 and Pax6 was reduced in OS-supplemented groups with high circulating levels of GLP-1, suggesting a different mechanism in the increased density of L-cells. In this respect, it should be noted that although EECs are still classified according to their major/unique hormone product (as for example GLP-1 for L-cells), it is now acknowledged that EEC are multihormonal [Habib et al., 2012; Engelstoft et al., 2013; Grunddal et al., 2016]. In particular, very recent data demonstrated that mature differentiated EECs display hormonal plasticity allowing them to change their hormonal products in response to extrinsic factor, such as bone morphogenic proteins (BMP), during their migration along the crypt-villus axis [Beumer et al., 2018; Gehart et al., 2019]. Thus, the increased L-cell density observed here may be the result of direct effect of OS on this plasticity to produce more GLP-1, independently of early markers of EEC proliferation and differentiation. Interestingly, in the present study, the production of CCK, a key early-satiety peptide, was not affected by OS supplementation (data not shown) reinforcing the specific impact of OS on EEC to produce GLP-1 and PYY in a segment of gut 
where CCK is not predominantly produced. How OS can modulate both EEC subtypes identity and/or GI peptide expression by acting on extrinsic factor (such villus-produced BMP) need to be further investigated.

\section{What are the putative mediators of the massive effect of neonatal OS supplementation on ileal L-cells?}

The identification of the small intestine, rather than the colon, as a privileged site for the action of the OS on transcriptional activity that we observed, has been previously reported in studies involving adult animals [Everard et al. 2011; Cani et al 2009a]. Conventionalization of germ-free mice led to similar observations [Larsson et al., 2012; Sommer et al., 2015; Arora et al., 2017]. However, a nutritional modulation as in our study by OS supplementation may differently impact ileal epithelium as compared to absence/presence of microbiota. As for example, in the Arora's study, conventionalization of germ-free mice led to downregulation of GLP-1 secreting vesicle process in L-cells whereas we observed an increase in GLP-1 and PYY production. These opposite data may also result from great differences in age of animals in these studies. Nevertheless, our data raise the question of how OS modulation of microbiota could act on ileal L-cells. The well- known capacity of SCFA (mainly butyrate but also propionate or even, non-consensually, acetate) to stimulate PYY and/or GLP-1 production [Plaisancié et al 1995; Plaisancié et al 1996; Zhou et al 2006; Zhou et al 2008; Tolhurst et al, 2012; Larraufie et al 2018] seems inconsistent with our observation of a OS-impact mainly localized in the ileum, in a context of no propionate/butyrate synthesis.

Among others potential mechanisms are the acidification of the luminal milieu or changes in pathogens associated molecular patterns (PAMPs). Indeed, Zhou et al (2008) have shown that changes in pH from 7.5 to 6.5 induce per se an increase in Gcg expression by STC-1 cells in vitro. Otherwise, it is known that EECs have receptors for PAMPs (i.e. Toll-like receptors) [see for review van de Wouw et al. 2017 and Plovier \& Cani, 2017]. This is of particular interest since Panwar et al [2016] have recently demonstrated that some bacterial strains elicit GLP-1 secretion through signaling agents of the toll-like receptor system, as illustrated by the fact that blockade of MyD88 triggers bacteria-induced GLP-1 secretion.

\section{OS impact on eating behavior, usually observed simultaneously with their consumption, does not seem to be programmable}

Despite a certain disparity in the literature [e.g. Hess et al 2011], possibly related to the heterogeneity in dosages or methodologies, several studies have reported beneficial effect of OS prebiotics - mainly fructans but also $\alpha \mathrm{GOS}$, on adult eating behavior, such as attenuated hunger sensation, increased satiety or reduced energy intake in either healthy volunteers [Cani et al., 2009b; Pedersen et al 2013] or overweight adults [Morel et al 2015b; Reimer et al 2017]. To note, the existing literature does not establish whether this is also true in infants who are however frequently supplemented with prebiotics. In agreement with human data, decreased food/energy intakes have been evidenced in adult rodents supplemented with fructans [Cani et al 2004; Parnell \& Reimer 2012] or aGOS [Overduin et al 2013]. In both models, these effects have been related to SCFA production by colonic bacteria during OS supplementation. Each of the 3 main SCFA namely, acetate, propionate and butyrate, has been demonstrated to reduce energy intake, particularly in rodent model of diet-induced obesity [Lin et al, 2012; Frost et al 2014, Li et al, 2018] although conflicting results are reported [Perry et al., 2016; Canfora \& Blaak 2017], probably depending on the mode (orogastric, intraperitoneal, intracerebroventricular, colonic delivery via fermentable fibers, etc.) and duration (acute vs chronic) of SCFA or SCFA precursors administration. In humans, this assumption has been substantiated for both acetate and propionate by numerous studies dealing with appetite-related parameters [see for review Darzi et al 2011] as well as by the observations of reduced hedonic response to high-energy foods regulated in striatum [Byrne et al., 2016] or reduced energy intake following administration of propionate precursors in overweight adults [Chambers et al., 2015; Byrne et al, 2019]. Whether these SCFA regulate appetite directly at hypothalamic level [Frost et al. 2014] or via a vagally-dependent mechanism [Perry et al., 2016; Li et al, 2018] implying or not enhanced intestinal satiety peptide (GLP-1 and PYY) following interaction of SCFA with FFAR receptors on L-cells is still a matter of experimental research in animal models or clinical trials in humans [van de Wouvet al, 2017].

Since each of the actors of the microbiota-EEC-brain axis appears to be long-lastingly impacted by perinatal environment [Estienne et al., 2010; Morel et al, .2015a, Ross and Desai, 2014; Ndjim et al., 2017], we had assumed that early microbiota modulation associated with changes in EEC could program adult eating behavior, what has remained unexplored until now. However, this hypothesis could not be supported in the present study, since eating behavior at adulthood did not appear significantly affected by early life OS supplementation which however had increased total SCFA, concomitantly with increased GLP-1 and PYY release and L-cells density at the end of supplementation. This lack of eating behavior programming indicates that none of the presupposed events (i.e. programming of EEC or vagal sensitivity and/or microbiota programming) has occurred in our conditions. Indeed we did not observe any differences in c-Fos expression in the rat brainstem at adulthood $2 \mathrm{~h}$ after a glucose bolus (data not shown). It thus seems that depending of the nature of perinatal stress (maternal protein restriction [Ndjim et al., 2017] or maternal deprivation [Etienne et al., 2010] or postnatal modulation of microbiota by OS) the long-lasting impact is not systematic. For microbiota, the lack of programming could be related to an inadequacy of the timing when modulation was applied, as discussed below.

\section{Is programming of the microbiota subjected to a particular timing?}

In this study, we did not observe any programming impact of any of the neonatal OS supplementations on adult microbiota. This result is in line with what we had previously observed for FOS [Morel et al 2015a] but contradicts the small-scale programming found after neonatal supplementation with GOS/In in this same study. This discrepancy may result from the difference in the method used for analyzing microbiotal 
composition, even if it is counterintuitive since $16 \mathrm{~S}$ sequencing used here is more exhaustive than qPCR used previously. Because this impact was minor, it could also have not been reproduced in our new experimental conditions such as a new batch of animals, a different room of our animal facility, or even possible slight difference in the composition of the semi-purified diets we used, knowing that all these parameters are known to affect the microbiota of laboratory animals [see for review Tomas et al, 2012].

Such a disappearance of the effect, yet drastic, found in our animals at the end of supplementation raises the question of the most favorable period for a sustainable modulation of the composition of the microbiota. Indeed, in our experimental protocols, prebiotic supplementation was applied during a short postnatal period and completed before the start of solid food consumption, whereas the studies reporting programming effects of early supplementation with OS on the subsequent composition of the microbiota were based on longer-term supplements extending from the prenatal period (i.e. supplementation of gestating mothers) to complete weaning or even further [Fugiwara et al 2010; Le Bourgot et al 2019]. Whether the supplementation we applied was insufficiently early, insufficiently late or insufficiently sustained is difficult to establish on the sole basis of this comparison. However, in Fugiwara et al's study, a difference in adult microbiota composition was solely observed for mice offsprings whose supplementation with FOS was maintained beyond weaning. Whether this was also true in Le Bourgot et al's study cannot be evaluated since all piglets were supplemented with FOS for a few weeks after weaning.

From this, one could assume that to be lastingly effective, prebiotics must be able to exert their microbiotal effect after full weaning and thereby control the impacts of new bacterial sources and changes in dynamics of bacterial populations that are resulting from the switch from maternal milk to solid food, which is actually associated with dramatic changes in microbiota composition and activity both in human [Koenig et al 2011] and rat [Inoue \& Ushida, 2003; Fança-Berthon et al 2010]. This hypothesis would explain why the early-life events that are known to affect neonatal microbiota composition (i.e. birth mode, infant feeding...) are not associated with significant variations in adult microbiota composition [Falony et al 2016], but it requires strict comparisons between time windows of supplementation to be validated.

\section{All OS studied performed similarly despite differences in their chemical characteristics}

In our study, the 3 studied OS have led to very comparable results both in terms of microbiotal impact and physiological repercussions. With regard to microbiotal changes, the observed modifications, in particular the acidification of the contents, the less diversified production of SCFA and the lesser richness of the microbiota, suggest that OS delayed bacterial diversification. This is reminiscent of what supposedly occurs in breast-fed babies compared with babies fed unsupplemented formulas [Mackie et al 1999; Le Huërou-Luron et al 2010]. This similarity is quite surprising in that the chemical nature of the constituent monomers and the pattern of glycosidic linkages in different OS products are expected to influences the abilities of individual bacteria to grow on them [see for reviews Macfarlane et al 2008, Louis et al 2016]. However, our results are consistent with Harris et al's findings [2017], that the orientation of glycosidic linkage is not a main driver of SCFA production profile, that, when it intervenes, its action would rather concern proportion of butyrate, a SCFA poorly produced in our immature animals. Moreover, they also agree with the similarities of microbiotal impacts reported between $\beta G O S$ and FOS on the one hand [Burokas et al 2017], and between $\alpha$ GOS and $\beta$ GOS on the other hand [Fehlbaum et al 2017].

Thus, our study confirms the prebiotic character of $\alpha \mathrm{GOS}$ and, in addition, extends the well-known activity of FOS and GOS/In as satiety enteropeptides secretagogue to this new prebiotic, what accords with its satietogenic effect described in humans [Morel et al 2015b].

\section{Conclusions}

In conclusion, our study depicts that the ability of OS to modulate the EEC, previously described in adults, also operates in the neonatal period, despite the immaturity of the microbiota at this time. This observation thus calls into question the nature of the mediators actually involved, as supposed until now. In addition, our in-depth study of the OS-impacts on the genes regulating the differentiation of EEC precursors questions the current understanding of the ontogenesis of these cells.

Finally, our results do not demonstrate any programming effect of OS neither on EEC and food consumption nor on adult microbiota constitution. If this holds true for humans, this is reassuring considering that the current study investigated type and doses of OS mimicking some of those commonly prescribed in formula for toddlers.

Supplementary Materials:

Figure S1: Postnatal growth of suckling rats in the different groups of OS supplementation,

Table S1: Primers sequences,

Figure S2: Growth of weaned rats until adulthood,

Figure S3: Relative expression of gene implied in the endocrine lineage and in L-cells differentiation in the colon.

Figure S4: Hierarchical clustering based on the Ward's method of phylogenetically informed distance matrix computed using the unweighted UniFrac metric for cecocolonic contents collected at PND 124/126,

Table S2: Concentration of SCFA in ileal and ceco-colonic contents at PND 124/126 
Author Contributions: C.M., G.L.D and M.R.D conceived and designed the experiments with the help of PP; C.M., M.R.D., GLD and A.L.P. performed the experiments; A.L.P., A.P. and I.G. contributed to biological analyses; C.M., G.L.D and H.B. analyzed the data and prepared figures; G.L.D. and C.M. drafted the manuscript. E.C. and P.P. revised the manuscript.

Funding: The present study was partly funded by OLYGOSE.

Acknowledgments: Authors thank Vincent Paillé and Fanny Morel for their scientific advices; Edith Gouyon, Aurélie Reufflet, Agnès David-Sochard, Martine Rival, Guillaume Poupeau and Elise Beneteau for their technical assistance. They are also grateful to the Genotoul platforms (Get PlaGe, Genotoul-bioinfo and Sigenae, INRA,Toulouse-Midi-Pyrénées) for 16 s sequencing and for providing help in computing and storage resources thanks to Galaxy instance.

Conflicts of Interest: The authors declare that they had a financial relationship with the organization that partly sponsored the research. E.C. is employee of Olygose.

\section{References}

> Arora T, Akrami R, Pais R, Bergqvist L, Johansson BR, Schwartz TW, Reimann F, Gribble FM, Bäckhed F. Microbial regulation of the $L$ cell transcriptome. Sci Rep. 2018;8(1):1207. doi: 10.1038/s41598-017-18079-2.

$>$ Berthoud HR, Sutton GM, Townsend RL, Patterson LM, Zheng H. Brainstem mechanisms integrating gut-derived satiety signals and descending forebrain information in the control of meal size. Physiol Behav. 2006;89[4]:517-24.

> Beucher A, Gjernes E, Collin C, Courtney M, Meunier A, et al. (2012) The Homeodomain-Containing Transcription Factors Arx and Pax4 Control Enteroendocrine Subtype Specification in Mice. PLoS ONE 7(5): e36449. doi:10.1371/journal.pone.0036449.

$>$ Beumer J, Artegiani B, Post Y, Reimann F, Gribble F, Nguyen TN, Zeng H, Van den Born M, Van Es JH, Clevers H. Enteroendocrine cells switch hormone expression along the crypt-to-villus BMP signalling gradient. Nat Cell Biol. 2018 Aug;20(8):909-916. doi: 10.1038/s41556-018-0143-y.

> Burokas A, Arboleya S, Moloney RD, Peterson VL, Murphy K, Clarke G, Stanton C, Dinan TG, Cryan JF.Targeting the Microbiota-Gut-Brain Axis: Prebiotics Have Anxiolytic and Antidepressant-like Effects and Reverse the Impact of Chronic Stress in Mice. Biol Psychiatry. 2017;82(7):472-487. doi: 10.1016/j.biopsych.2016.12.031.

> Byrne CS, Chambers ES, Alhabeeb H, Chhina N, Morrison DJ, Preston T, Tedford C, Fitzpatrick J, Irani C, Busza A, Garcia-Perez I, Fountana S, Holmes E, Goldstone AP, Frost GS. Increased colonic propionate reduces anticipatory reward responses in the human striatum to high-energy foods. Am J Clin Nutr. 2016;104(1):5-14. doi: 10.3945/ajcn.115.126706.Byrne CS, Chambers ES, Preston T, Tedford C, Brignardello J, Garcia-Perez I, Holmes E, Wallis GA, Morrison DJ, Frost GS. Effects of Inulin Propionate Ester Incorporated into Palatable Food Products on Appetite and Resting Energy Expenditure: A Randomised Crossover Study. Nutrients. 2019 Apr 16;11(4). pii: E861. doi: 10.3390/nu11040861.

> Canfora EE, Blaak EE. Acetate: a diet-derived key metabolite in energy metabolism: good or bad in context of obesity and glucose homeostasis? Curr Opin Clin Nutr Metab Care. 2017;20(6):477-483. doi: 10.1097/MCO.0000000000000408.

$>$ Cani PD , Dewever C, Delzenne NM. Inulin-type fructans modulate gastrointestinal peptides involved in appetite regulation (glucagon-like peptide-1 and ghrelin) in rats. Br J Nutr. 2004;92(3):521-6.

> Cani PD, Neyrinck AM, Maton N, Delzenne NM. Oligofructose promotes satiety in rats fed a high-fat diet: involvement of glucagon-like Peptide-1. Obes Res. 2005;13(6):1000-7.

$>$ Cani PD, Hoste S, Guiot Y, Delzenne NM. Dietary non-digestible carbohydrates promote L-cell differentiation in the proximal colon of rats. Br J Nutr. 2007;98(1):32-7.

> Cani PD, Possemiers S, Van de Wiele T, Guiot Y, Everard A, Rottier O, Geurts L, Naslain D, Neyrinck A, Lambert DM, Muccioli GG, Delzenne NM. Changes in gut microbiota control inflammation in obese mice through a mechanism involving GLP-2-driven improvement of gut permeability. Gut. 2009a;58(8):1091-103. doi: 10.1136/gut.2008.165886.

$>$ Cani PD, Lecourt E, Dewulf EM, Sohet FM, Pachikian BD, Naslain D, De Backer F, Neyrinck AM, Delzenne NM. Gut microbiota fermentation of prebiotics increases satietogenic and incretin gut peptide production with consequences for appetite sensation and glucose response after a meal._Am J Clin Nutr. 2009b ;90(5):1236-43. doi: 10.3945/ajcn.2009.28095.

> Caporaso JG, Lauber CL, Walters WA, Berg-Lyons D, Lozupone CA, Turnbaugh PJ, Fierer N, Knight R. Global patterns of 16S rRNA diversity at a depth of millions of sequences per sample Proc Natl Acad Sci U S A. 2011;108 Suppl 1:4516-22. doi: $10.1073 /$ pnas. 1000080107.

> Chambers ES, Viardot A, Psichas A, Morrison DJ, Murphy KG, Zac-Varghese SE, MacDougall K, Preston T, Tedford C, Finlayson GS, Blundell JE, Bell JD, Thomas EL, Mt-Isa S, Ashby D, Gibson GR, Kolida S, Dhillo WS, Bloom SR, Morley W, Clegg S, Frost G. Effects of targeted delivery of propionate to the human colon on appetite regulation, body weight maintenance and adiposity in overweight adults. Gut. 2015 ;64(11):1744-54. doi: 10.1136/gutjnl-2014-307913.

$>$ Combes S, Massip K, Martin O, Furbeyre H, Cauquil L, Pascal G, Bouchez O, Le Floc'h N, Zemb O, Oswald IP, Gidenne T. Impact of feed restriction and housing hygiene conditions on specific and inflammatory immune response, the cecal bacterial community and the survival of young rabbits. Animal. 2017;11(5):854-863. doi: $10.1017 /$ S1751731116002007.

> Coupé B, Delamaire E, Hoebler C, Grit I, Even P, Fromentin G, Darmaun D, Parnet P. Hypothalamus integrity and appetite regulation in low birth weight rats reared artificially on a high-protein milk formula. J Nutr Biochem. 2011;22(10):956-63. doi: 10.1016/j.jnutbio.2010.08.007. 
> Coupé B, Grit I, Hulin P, Randuineau G, Parnet P (2012) Postnatal Growth after Intrauterine Growth Restriction Alters Central Leptin Signal and Energy Homeostasis. PLoS ONE 7(1): e30616. doi:10.1371/journal.pone.0030616.

$>$ Cripps RL, Martin-Gronert MS, Ozanne SE. Fetal and perinatal programming of appetite. Clin Sci 2005;109:1-11.

> Darzi J, Frost GS, Robertson MD. Do SCFA have a role in appetite regulation? Proc Nutr Soc. 2011;70(1):119-28. doi: 10.1017/S0029665110004039.

> De Cosmi V, Scaglioni S, Agostoni C. Early Taste Experiences and Later Food Choices. Nutrients. 2017;9(2). pii: E107. doi: 10.3390/nu9020107.

$>$ Delzenne NM, Cani PD, Neyrinck AM. Modulation of glucagon-like peptide 1 and energy metabolism by inulin and oligofructose: experimental data.J Nutr. 2007;137(11 Suppl):2547S-2551S. doi: 10.1093/jn/137.11.2547S.

> Desai M, Gayle D, Han G, Ross MG. Programmed hyperphagia due to reduced anorexigenic mechanisms in intrauterine growth-restricted offspring. Reprod Sci. 2007; 14(4):329-337.

$>$ Engelstoft MS, Egerod KL, Lund ML, Schwartz TW. Enteroendocrine cell types revisited. Curr Opin Pharmacol. 2013 Dec;13(6):912-21. doi: 10.1016/j.coph.2013.09.018.

D Escudié F, Auer L, Bernard M, Mariadassou M, Cauquil L, Vidal K, Maman S, Hernandez-Raquet G, Combes S, Pascal G. FROGS: Find, Rapidly, OTUs with Galaxy Solution. Bioinformatics. 2018 15;34(8):1287-1294. doi: 10.1093/bioinformatics/btx791.

Dstienne M, Claustre J, Clain-Gardechaux G, Paquet A, Taché Y, Fioramonti J, Plaisancié P. Maternal deprivation alters epithelial secretory cell lineages in rat duodenum: role of CRF-related peptides. Gut. $2010 ; 59(6): 744-51$. doi: 10.1136/gut.2009.190728.

> Everard A, Lazarevic V, Derrien M, Girard M, Muccioli GG, Neyrinck AM, Possemiers S, Van Holle A, François P, de Vos WM, Delzenne NM, Schrenzel J, Cani PD. Responses of gut microbiota and glucose and lipid metabolism to prebiotics in genetic obese and diet-induced leptin-resistant mice. Diabetes. 2011;60(11):2775-86. doi: 10.2337/db11-0227.

> Falony G, Joossens M, Vieira-Silva S, Wang J, Darzi Y, Faust K, Kurilshikov A, Bonder MJ, Valles-Colomer M, Vandeputte D, Tito RY, Chaffron S, Rymenans L, Verspecht C, De Sutter L, Lima-Mendez G, D'hoe K, Jonckheere K, Homola D, Garcia R, Tigchelaar EF, Eeckhaudt L, Fu J, Henckaerts L, Zhernakova A, Wijmenga C, Raes J. Population-level analysis of gut microbiome variation. Science. 2016;352(6285):560-4. doi: 10.1126/science.aad3503.

> Fança-Berthon P, Hoebler C, Mouzet E, David A, Michel C. Intrauterine growth restriction not only modifies the cecocolonic microbiota in neonatal rats but also affects its activity in young adult rats. J Pediatr Gastroenterol Nutr. 2010;51(4):402-13. doi: 10.1097/MPG.0b013e3181d75d52.

> Fehlbaum S, Prudence K, Kieboom J, Heerikhuisen M, van den Broek T, Schuren FHJ, Steinert RE, Raederstorff D. In Vitro Fermentation of Selected Prebiotics and Their Effects on the Composition and Activity of the Adult Gut Microbiota. Int J Mol Sci. 2018;19(10). pii: E3097. doi: 10.3390/ijms19103097.

$>$ Fetissov SO. Role of the gut microbiota in host appetite control: bacterial growth to animal feeding behaviour. Nat Rev Endocrinol. 2017;13(1):11-25. doi: 10.1038/nrendo.2016.150.

> Frost G, Sleeth ML, Sahuri-Arisoylu M, Lizarbe B, Cerdan S, Brody L, Anastasovska J, Ghourab S, Hankir M, Zhang S, Carling D, Swann JR, Gibson G, Viardot A, Morrison D, Louise Thomas E, Bell JD. The short-chain fatty acid acetate reduces appetite via a central homeostatic mechanism. Nat Commun. 2014;5:3611. doi: $10.1038 /$ ncomms4611.

$>$ Fujiwara R, Takemura N, Watanabe J, Sonoyama K. Maternal consumption of fructo-oligosaccharide diminishes the severity of skin inflammation in offspring of NC/Nga mice. Br J Nutr. 2010;103(4):530-8. doi: 10.1017/S000711450999198X.

> Gaetani S, Romano A, Provensi G, Ricca V, Lutz T, Passani MB. Eating disorders: from bench to bedside and back.J Neurochem. 2016;139(5):691-699. doi: 10.1111/jnc.13848.

> Gehart H, van Es JH, Hamer K, Beumer J, Kretzschmar K, Dekkers JF, Rios A, Clevers H. Identification of Enteroendocrine Regulators by Real-Time Single-Cell Differentiation Mapping. Cell. 2019;176(5):1158-1173.e16. doi: 10.1016/j.cell.2018.12.029

> Glenny EM, Bulik-Sullivan EC2, Tang Q2, Bulik CM1,3,4, Carroll IM5,6. Eating Disorders and the Intestinal Microbiota: Mechanisms of Energy Homeostasis and Behavioral Influence. Curr Psychiatry Rep. 2017;19(8):51. doi: 10.1007/s11920-017-0797-3.

> Grigoryan M, Kedees MH, Charron MJ, Guz Y, Teitelman G. Regulation of Mouse Intestinal L Cell Progenitors Proliferation by the Glucagon Family of Peptides. Endocrinology 2012 ; 153: 3076-3088. doi: 10.1210/en.2012-1120.

$>$ Grunddal KV, Ratner CF, Svendsen B, Sommer F, Engelstoft MS, Madsen AN, Pedersen J, Nøhr MK, Egerod KL, Nawrocki AR, Kowalski T, Howard AD, Poulsen SS, Offermanns S, Bäckhed F, Holst JJ, Holst B, Schwartz TW. Neurotensin Is Coexpressed, Coreleased, and Acts Together With GLP-1 and PYY in Enteroendocrine Control of Metabolism. Endocrinology. 2016;157(1):176-94. doi: 10.1210/en.2015-1600.

> Habib AM, Richards P, Cairns LS, Rogers GJ, Bannon CA, Parker HE, Morley TC, Yeo GS, Reimann F, Gribble FM. Overlap of endocrine hormone expression in the mouse intestine revealed by transcriptional profiling and flow cytometry. Endocrinology. 2012;153(7):3054-65. doi: 10.1210/en.2011-2170.

$>$ Harris HC, Edwards CA, Morrison DJ. Impact of Glycosidic Bond Configuration on Short Chain Fatty Acid Production from Model Fermentable Carbohydrates by the Human Gut Microbiota. Nutrients. 2017;9(1). pii: E26. doi: 10.3390/nu9010026.

$>$ Hess JR, Birkett AM, Thomas W, Slavin JL. Effects of short-chain fructooligosaccharides on satiety responses in healthy men and women. Appetite. 2011;56(1):128-34. doi: 10.1016/j.appet.2010.12.005.

$>$ Inoue R \& Ushida K. Development of the intestinal microbiota in rats and its possible interactions with the evolution of the luminal IgA in the intestine. FEMS Microbiol Ecol 2003; 45: 147-153.

$>$ Koenig JE, Spor A, Scalfone N, Fricker AD, Stombaugh J, Knight R, Angenent LT, Ley RE. Succession of microbial consortia in the developing infant gut microbiome. Proc Natl Acad Sci U S A. 2011;108 Suppl 1:4578-85. doi: 10.1073/pnas.1000081107. 
$>\quad$ Kok, N.N., Morgan, L.M., Williams, C.M., Roberfroid, M.B., Thissen, J.P., Delzenne, N.M. Insulin, glucagon-like peptide 1, glucose-dependent insulinotropic polypeptide and insulin-like growth factor I as putative mediators of the hypolipidemic effect of oligofructose in rats. J Nutr. 1998, 128, 1099-103

$>$ Lalles JP, Michel C, Theodorou V, Segain JP. (2016). Epigenetic regulation of gastrointestinal epithelial barrier and developmental origin of health and disease. In: Rosenfeld CS, The Epigenome and Developmental Origins of Health and Disease (p. 337-360). USA : Academic Press., DOI : 10.1016/B978-0-12-801383-0.00017-7.

$>$ Lam YY, Maguire S, Palacios T, Caterson ID. Are the Gut Bacteria Telling Us to Eat or Not to Eat? Reviewing the Role of Gut Microbiota in the Etiology, Disease Progression and Treatment of Eating Disorders. Nutrients 2017, 9, 602; doi:10.3390/nu9060602.

$>$ Larraufie P, Martin-Gallausiaux C, Lapaque N, Dore J, Gribble FM, Reimann F, Blottiere HM. SCFAs strongly stimulate PYY production in human enteroendocrine cells. Sci Rep. 2018;8(1):74. doi: 10.1038/s41598-017-18259-0.

$>$ Larsson E, Tremaroli V, Lee YS, Koren O, Nookaew I, Fricker A, Nielsen J, Ley RE, Bäckhed F. Analysis of gut microbial regulation of host gene expression along the length of the gut and regulation of gut microbial ecology through MyD88. Gut. 2012 Aug;61(8):1124-31. doi: 10.1136/gutjnl-2011-301104.

> Le Blay G, Michel C, Blottière HM, Cherbut C. Prolonged intake of fructo-oligosaccharides induces a short-term elevation of lactic acid-producing bacteria and a persistent increase in cecal butyrate in rats. $J$ Nutr. $1999 ; 129(12): 2231-5$.

$>$ Le Bourgot C, Ferret-Bernard S, Apper E, Taminiau B, Cahu A, Le Normand L, Respondek F, Le Huërou-Luron I, Blat S. Perinatal short-chain fructooligosaccharides program intestinal microbiota and improve enteroinsular axis function and inflammatory status in high-fat diet-fed adult pigs. FASEB J. 2019;33(1):301-313. doi: 10.1096/fj.201800108R.

$>$ Le Huërou-Luron I, Blat S, Boudry G. Breast- v. formula-feeding: impacts on the digestive tract and immediate and long-term health effects. Nutr Res Rev. 2010;23(1):23-36. doi: 10.1017/S0954422410000065.

$>$ Li HJ, Ray SK, Singh NK, Johnston B, Leiter AB. Basic helix-loop-helix transcription factors and enteroendocrine cell differentiation. Diabetes Obes Metab. 2011 Oct;13 Suppl 1:5-12. doi: 10.1111/j.1463-1326.2011.01438.x.

$>$ Li Z, Yi CX, Katiraei S, Kooijman S, Zhou E, Chung CK, Gao Y, van den Heuvel JK, Meijer OC, Berbée JFP, Heijink M, Giera M, Willems van Dijk K, Groen AK, Rensen PCN, Wang Y. Butyrate reduces appetite and activates brown adipose tissue via the gut-brain neural circuit. Gut. 2018 Jul;67(7):1269-1279. doi: 10.1136/gutjnl-2017-314050.

$>$ Lin HV, Frassetto A, Kowalik EJ Jr, Nawrocki AR, Lu MM, Kosinski JR, Hubert JA, Szeto D, Yao X, Forrest G, Marsh DJ. Butyrate and propionate protect against diet-induced obesity and regulate gut hormones via free fatty acid receptor 3-independent mechanisms.PLoS One. 2012;7(4):e35240. doi: 10.1371/journal.pone.0035240.

$>$ Lindsay AC, Sitthisongkram S, Greaney ML, Wallington SF, Ruengdej P. Non-Responsive Feeding Practices, Unhealthy Eating Behaviors, and Risk of Child Overweight and Obesity in Southeast Asia: A Systematic Review. Int J Environ Res Public Health. 2017;14(4). pii: E436. doi: 10.3390/ijerph14040436.

$>$ Liu F, Li P, Chen M, Luo Y, Prabhakar M, Zheng H, He Y, Qi Q, Long H, Zhang Y, Sheng H, Zhou H. Fructooligosaccharide (FOS) and Galactooligosaccharide (GOS) Increase Bifidobacterium but Reduce Butyrate Producing Bacteria with Adverse Glycemic Metabolism in healthy young population. Sci Rep. 2017;7(1):11789. doi: 10.1038/s41598-017-10722-2.

$>$ Louis P, Flint HJ, Michel C. How to Manipulate the Microbiota: Prebiotics. Adv Exp Med Biol. 2016;902:119-42. doi: 10.1007/978-3-319-31248-4_9.

$>$ Lussana, F.; Painter, R.C.; Ocke, M.C.; Buller, H.R.; Bossuyt, P.M.; Roseboom, T.J. Prenatal exposure to the Dutch famine is associated with a preference for fatty foods and a more atherogenic lipid profile. Am. J. Clin. Nutr. 2008, 88, 1648-1652.

$>$ Macfarlane GT, Steed H, Macfarlane S. Bacterial metabolism and health-related effects of galacto-oligosaccharides and other prebiotics. J Appl Microbiol. 2008;104(2):305-44. doi: 10.1111/j.1365-2672.2007.03520.x.

$>$ Mackie RI, Sghir A, Gaskins HR. Developmental microbial ecology of the neonatal gastrointestinal tract. Am J Clin Nutr 1999;69:1035S-45S.

> MacLean PS, Blundell JE, Mennella JA, Batterham RL. Biological control of appetite: A daunting complexity. Obesity (Silver Spring). 2017 ;25 Suppl 1:S8-S16. doi: 10.1002/oby.21771.

$>$ Martin Agnoux A, Alexandre-Gouabau MC, Le Dréan G, Antignac JP, Parnet P. Relative contribution of foetal and post-natal nutritional periods on feeding regulation in adult rats. Acta Physiol (Oxf). 2014;210(1):188-201. doi: 10.1111/apha.12163.

$>$ Maurer AD, Chen Q, McPherson C, Reimer RA. Changes in satiety hormones and expression of genes involved in glucose and lipid metabolism in rats weaned onto diets high in fibre or protein reflect susceptibility to increased fat mass in adulthood. J Physiol. $2009 ; 587(3): 679-91$. doi: 10.1113/jphysiol.2008.161844.

$>$ Midtvedt AC, Midtvedt T. Production of short chain fatty acids by the intestinal microflora during the first 2 years of human life. J Pediatr Gastroenterol Nutr. 1992;15(4):395-403.

$>$ Mischke M, Plösch T. More than just a gut instinct-the potential interplay between a baby's nutrition, its gut microbiome, and the epigenome. Am J Physiol Regul Integr Comp Physiol. 2013;304(12):R1065-9. doi: 10.1152/ajpregu.00551.2012.

$>$ Morel FB, Oozeer R, Piloquet H, Moyon T, Pagniez A, Knol J, Darmaun D, Michel C. Preweaning modulation of intestinal microbiota by oligosaccharides or amoxicillin can contribute to programming of adult microbiota in rats. Nutrition. 2015a;31(3):515-22. doi: 10.1016/j.nut.2014.09.011.

$>$ Morel FB, Dai Q, Ni J, Thomas D, Parnet P, Fança-Berthon P. $\alpha$-Galacto-oligosaccharides Dose-Dependently Reduce Appetite and Decrease Inflammation in Overweight Adults. J Nutr. 2015b;145(9):2052-9. doi: 10.3945/jn.114.204909.

> Morita C, Tsuji H, Hata T, Gondo M, Takakura S, Kawai K, Yoshihara K, Ogata K, Nomoto K, Miyazaki K, Sudo N. Gut Dysbiosis in Patients with Anorexia Nervosa. PLoS One. 2015 ;10(12):e0145274. doi: 10.1371/journal.pone.0145274.

$>$ Nair AB and Jacob S. A simple practice guide for dose conversion between animals and human. J Basic Clin Pharm. 2016; 7(2): 27-31. 
$>$ Ndjim M, Poinsignon C, Parnet P, Le Dréan G. Loss of Vagal Sensitivity to Cholecystokinin in Rats Born with Intrauterine Growth Retardation and Consequence on Food Intake. Front Endocrinol (Lausanne). 2017;8:65. doi: 10.3389/fendo.2017.00065

> Nijman RM, Liu Y, Bunyatratchata A, Smilowitz JT, Stahl B1, Barile D. Characterization and Quantification of Oligosaccharides in Human Milk and Infant Formula. J Agric Food Chem. 2018 ;66(26):6851-6859.

$>$ Orozco-Solis R, Lopes de Souza S, Barbosa Matos RJ, Grit I, Le Bloch J, et al. (2009) Perinatal undernutrition-induced obesity is independent of the developmental programming of feeding. Physiology \& Behavior 96: 481-492.

$>$ Overduin J, Schoterman MH, Calame W, Schonewille AJ, Ten Bruggencate SJ. Dietary galacto-oligosaccharides and calcium: effects on energy intake, fat-pad weight and satiety-related, gastrointestinal hormones in rats. Br J Nutr. 2013;109(7):1338-48. doi: 10.1017/S0007114512003066.

> Panwar H, Calderwood D, Gillespie AL, Wylie AR, Graham SF, Grant IR, Grover S, Green BD. Identification of lactic acid bacteria strains modulating incretin hormone secretion and gene expression in enteroendocrine cells. Journal of Functional Foods 23 (2016) 348-358

$>$ Paradis J, Boureau P, Moyon T, Nicklaus S, Parnet P, Paillé V. Perinatal Western Diet Consumption Leads to Profound Plasticity and GABAergic Phenotype Changes within Hypothalamus and Reward Pathway from Birth to Sexual Maturity in Rat. Front Endocrinol (Lausanne). 2017;8:216. doi: 10.3389/fendo.2017.00216.

$>$ Parnell JA, Reimer RA. Prebiotic fibres dose-dependently increase satiety hormones and alter Bacteroidetes and Firmicutes in lean and obese JCR:LA-cp rats. Br J Nutr. 2012;107(4):601-13. doi: 10.1017/S0007114511003163.

$>$ Parnet P, Paillé V, Bolaños Jimenez F, Kaeffer B, Schaal B, Bouret SG, Amarger V. [The sensory and nutritional experience of parents guide offsprings' feeding behavior].[Article in French] Med Sci (Paris). 2016;32(1):85-92. doi: 10.1051/medsci/20163201014.

> Perälä MM, Männistö S, Kaartinen NE, Kajantie E, Osmond C, Barker DJ, Valsta LM, Eriksson JG. Body size at birth is associated with food and nutrient intake in adulthood. PLoS One. 2012;7(9):e46139. doi: 10.1371/journal.pone.0046139.

> Perry RJ, Peng L, Barry NA, Cline GW, Zhang D, Cardone RL, Petersen KF, Kibbey RG, Goodman AL, Shulman GI. Acetate mediates a microbiome-brain- $\beta$-cell axis to promote metabolic syndrome. Nature. 2016;534(7606):213-7. doi: 10.1038/nature18309.

$>$ Plaisancié P, Dumoulin V, Chayvialle JA, Cuber JC. Luminal glucagon-like peptide-1(7-36) amide-releasing factors in the isolated vascularly perfused rat colon. J Endocrinol. 1995;145(3):521-6.

$>$ Plaisancié P, Dumoulin V, Chayvialle JA, Cuber JC. Luminal peptide YY-releasing factors in the isolated vascularly perfused rat colon. J Endocrinol. 1996;151(3):421-9.

$>$ Pedersen C, Lefevre S, Peters V, Patterson M, Ghatei MA, Morgan LM, Frost GS. Gut hormone release and appetite regulation in healthy non-obese participants following oligofructose intake. A dose-escalation study. Appetite. 2013;66:44-53. doi: 10.1016/j.appet.2013.02.017.

$>$ Pueta M1, Abate P, Haymal OB, Spear NE, Molina JC. Ethanol exposure during late gestation and nursing in the rat: effects upon maternal care, ethanol metabolism and infantile milk intake. Pharmacol Biochem Behav. 2008;91(1):21-31. doi: 10.1016/j.pbb.2008.06.007.

$>$ Plovier H \& Cani PD Enteroendocrine Cells: Metabolic Relays between Microbes and Their Host In Developmental Biology of Gastrointestinal Hormones, Wabitsch M, Posovszky C (eds), Endocr Dev. Basel, Karger, 2017, 32, $139-164$.

$>$ R Core Team (2018). R: A language and environment for statistical computing. R Foundation for Statistical Computing, Vienna, Austria. URL https://www.R-project.org/.

$>$ Rastall RA. Functional oligosaccharides: application and manufacture. Annu Rev Food Sci Technol 2010;1:305-39.

> Reimer RA, Willis HJ, Tunnicliffe JM, Park H, Madsen KL, Soto-Vaca A. Inulin-type fructans and whey protein both modulate appetite but only fructans alter gut microbiota in adults with overweight/obesity: A randomized controlled trial. Mol Nutr Food Res. 2017;61(11). doi: 10.1002/mnfr.201700484.

$>$ Reimer, R. A.; McBurney, M. I. Dietary fiber modulates intestinal proglucagon messenger ribonucleic acid and postprandial secretion of glucagon-like peptide-1 and insulin in rats. Endocrinology 1996, 137,3948 3956.

$>$ Ross MG, Desai M. Developmental programming of appetite/satiety. Ann Nutr Metab. 2014;64 Suppl 1:36-44. doi: $10.1159 / 000360508$.

$>$ Sabater, C., Prodanov, M., Olano, A., Corzo, N., Montilla, A. Quantification of prebiotics in commercial infant formulas. Food Chem. 2016, 194, 6-11.

> Savignac HM, Corona G, Mills H, Chen L, Spencer JP, Tzortzis G, Burnet PW. Prebiotic feeding elevates central brain derived neurotrophic factor, N-methyl-D-aspartate receptor subunits and D-serine. Neurochem Int. 2013 ;63(8):756-64. doi: 10.1016/j.neuint.2013.10.006.

$>$ Savignac HM, Couch Y, Stratford M, Bannerman DM, Tzortzis G, Anthony DC, Burnet PWJ. Prebiotic administration normalizes lipopolysaccharide (LPS)-induced anxiety and cortical 5-HT2A receptor and IL1- $\beta$ levels in male mice. Brain Behav Immun. 2016;52:120-131. doi: 10.1016/j.bbi.2015.10.007.

$>$ Schonhoff SE, Giel-Moloney M, Leiter AB. Minireview: Development and differentiation of gut endocrine cells. Endocrinology. $2004 ; 145(6): 2639-44$

$>$ Schwartz GJ. The role of gastrointestinal vagal afferents in the control of food intake: current prospects. Nutrition. $2000 ; 16(10): 866-73$.

> Sevrin T, Alexandre-Gouabau MC, Darmaun D, Palvadeau A, André A, Nguyen P, Ouguerram K, Boquien CY. Use of water turnover method to measure mother's milk flow in a rat model: Application to dams receiving a low protein diet during gestation and lactation. PLoS One. 2017;12(7):e0180550. doi: 10.1371/journal.pone.0180550.

$>$ Silva MT Saccharin aversion in the rat following adrenalectomy. Physiol Behav. 1977;19(2):239-44.

> Skórka A, Pieścik-Lech M, Kołodziej M, Szajewska H. Infant formulae supplemented with prebiotics: Are they better than unsupplemented formulae? An updated systematic review. Br J Nutr. 2018;119(7):810-825. doi: 10.1017/S0007114518000120.

$>$ Smith K, McCoy KD, Macpherson AJ. Use of axenic animals in studying the adaptation of mammals to their commensal intestinal microbiota. Semin Immunol. 2007;19(2):59-69. 
Sommer F, Nookaew I, Sommer N, Fogelstrand P, Bäckhed F. Site-specific programming of the host epithelial transcriptome by the gut microbiota. Genome Biol. 2015 Mar 28;16:62. doi: 10.1186/s13059-015-0614-4.

$>$ Sudo N, Chida Y, Aiba Y, Sonoda J, Oyama N, Yu XN, Kubo C, Koga Y. Postnatal microbial colonization programs the hypothalamic-pituitary-adrenal system for stress response in mice. J Physiol. 2004 Jul 1;558(Pt 1):263-75.

$>$ Tomas J, Langella P, Cherbuy C. The intestinal microbiota in the rat model: major breakthroughs from new technologies. Anim Health Res Rev. 2012 Jun;13(1):54-63

$>$ Tolhurst G, Heffron H, Lam YS, Parker HE, Habib AM, Diakogiannaki E, Cameron J, Grosse J, Reimann F, Gribble FM. Short-chain fatty acids stimulate glucagon-like peptide-1 secretion via the G-protein-coupled receptor FFAR2. Diabetes. 2012;61(2):364-71. doi: 10.2337/db11-1019.

$>$ van de Wouw M, Schellekens H, Dinan TG, Cryan JF. Microbiota-Gut-Brain Axis: Modulator of Host Metabolism and Appetite. J Nutr. 2017. pii: jn240481. doi: 10.3945/jn.116.240481.

$>$ van Deutekom AW, Chinapaw MJ, Jansma EP, Vrijkotte TG, Gemke RJ. The Association of Birth Weight and Infant Growth with Energy Balance-Related Behavior - A Systematic Review and Best-Evidence Synthesis of Human Studies. PLoS One. 2017;12(1):e0168186. doi: 10.1371/journal.pone.0168186.

> van Deutekom AW, Chinapaw MJ, Vrijkotte TG, Gemke RJ. The association of birth weight and postnatal growth with energy intake and eating behavior at 5 years of age - a birth cohort study. Int J Behav Nutr Phys Act. 2016;13:15.

$>$ Wang L, Hu L, Yan S, Jiang T, Fang S, Wang G, Zhao J, Zhang H, Chen W. Effects of different oligosaccharides at various dosages on the composition of gut microbiota and short-chain fatty acids in mice with constipation. Food Funct. 2017;8(5):1966-1978. doi: 10.1039/c7fo00031f.

$>$ Williams S, Chen L, Savignac HM, Tzortzis G, Anthony DC, Burnet PW. Neonatal prebiotic (BGOS) supplementation increases the levels of synaptophysin, GluN2A-subunits and BDNF proteins in the adult rat hippocampus. Synapse. $2016 ; 70(3): 121-4$. doi: 10.1002/syn.21880.

$>$ Wostmann BS. The germfree animal in nutritional studies. Annu Rev Nutr. 1981;1:257-79.

$>$ Zhou J, Hegsted M, McCutcheon KL, Keenan MJ, Xi X, Raggio AM, Martin RJ. Peptide YY and proglucagon mRNA expression patterns and regulation in the gut. Obesity (Silver Spring). 2006;14(4):683-9.

$>$ Zhou, J.,Martin, R. J., Tulley, R. T., Raggio, A. M. et al., Dietary resistant starch upregulates total GLP-1 and PYY in a sustained day-long manner through fermentation in rodents. Am. J. Physiol. Endocrinol. Metab. 2008, 295, E1160E1166.

(C) 2017 by the authors. Submitted for possible open access publication under the terms and conditions of the Creative Commons Attribution (CC BY) license (http://creativecommons.org/licenses/by/4.0/). 


\section{Supplementary data}

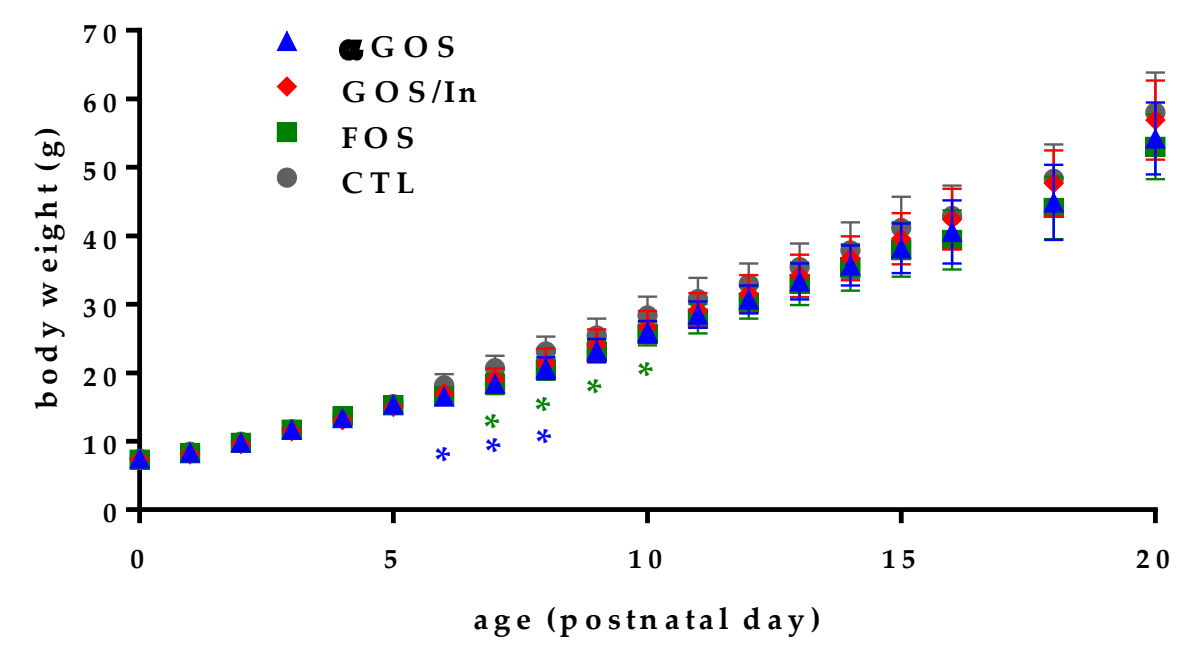

Figure S1. Postnatal growth of suckling rats in the different groups of OS supplementation. Data are means +/- SD collected from the total effective of rats ( $n=15-16$ per group). Asterisks indicate significant difference compared with CTL, their color refer to the treatment received between PND 5-14/15.

\begin{tabular}{|cccc|}
\hline Target & Forward primer & Reverse primer & Accession Number \\
\hline $\boldsymbol{\beta}$-actin & CTATCGGCAATGAGCGGTTCC & GCACTGTGTTGGCATAGAGGTC & NM_031144 \\
\hline Atoh1 & TGTTAGCAACG TGTGACTTC & CAGACCAGAGACAGAGATACG & NM_001109238 \\
\hline Gcg & CTAATGCTGGTACAAGGCAG & GTGAATGTGCCCTGTGAATG & NM_012707 \\
\hline Neurod1 & CACGCAGAAGGCAAG & TGGTCATGTTCCACTTCCTGT & NM_019218 \\
\hline Foxa1 & GTTCCGCACAGGGTTGGATA & CTGACCGGGACAGAGGAGTA & NM_012742 \\
\hline Neurog3 & Not available & Not available & NM_021700 \\
\hline Pax4 & CCCAAGGGTATTGGGGGAAG & GGATACACTGGGAGCCTTGTC & NM_031799 \\
\hline Pax6 & ATACCTACACCCCTCCGCAC & TGAGTCCTGTTGAAGTGGTTCC & NM_013001 \\
\hline PYY & AGCGGTATGGGAAAAGAGAAGTC & ACCACTGGTCCACACCTTCTG & NM_001034080 \\
\hline
\end{tabular}

Table S1. Primer sequences 


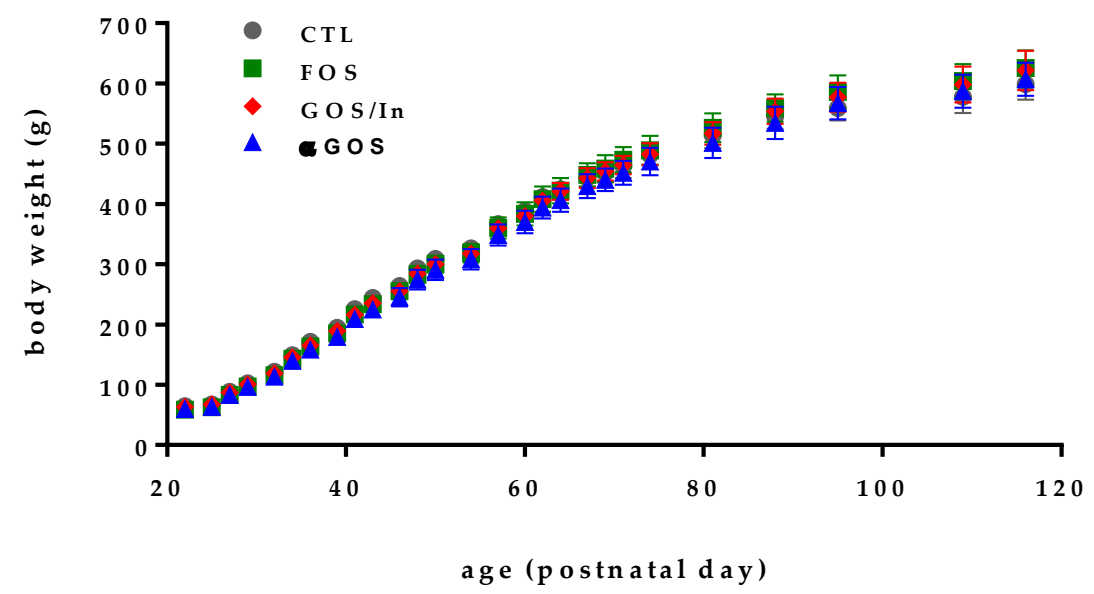

Figure S2. Growth of weaned rats until adulthood. Data are means $+/-\mathrm{SD}(\mathrm{n}=8$ per group). 

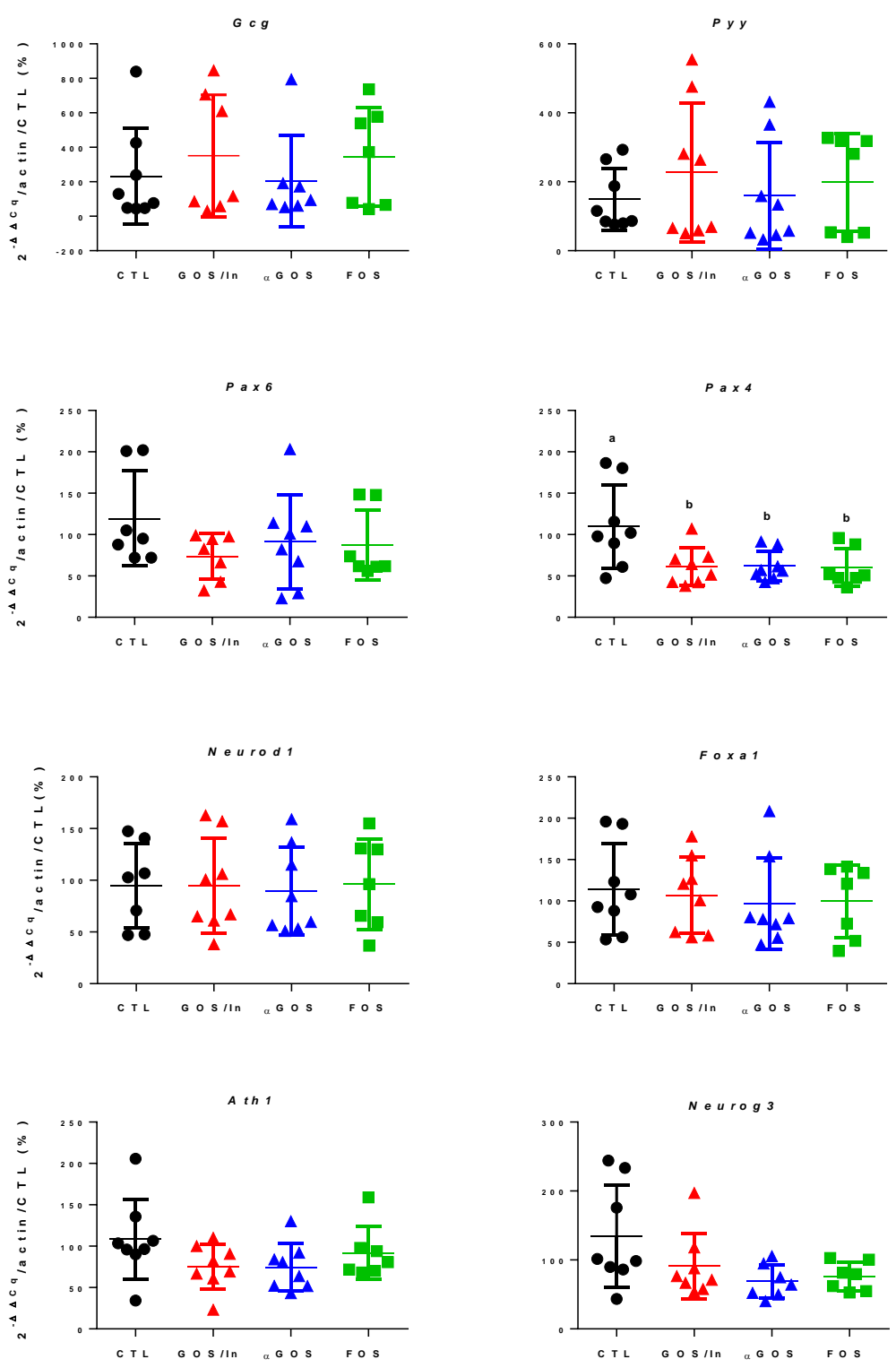

Figure S3. Relative expression of gene implied in the endocrine lineage and in L-cells differentiation in the colon. Different letters indicate significant difference between groups ( $p$ $<0.05$ ). Data are fold-change expressed in \% of CTL group. Individual, mean and SD values are plotted ( $n=7$ to 8 per group). 


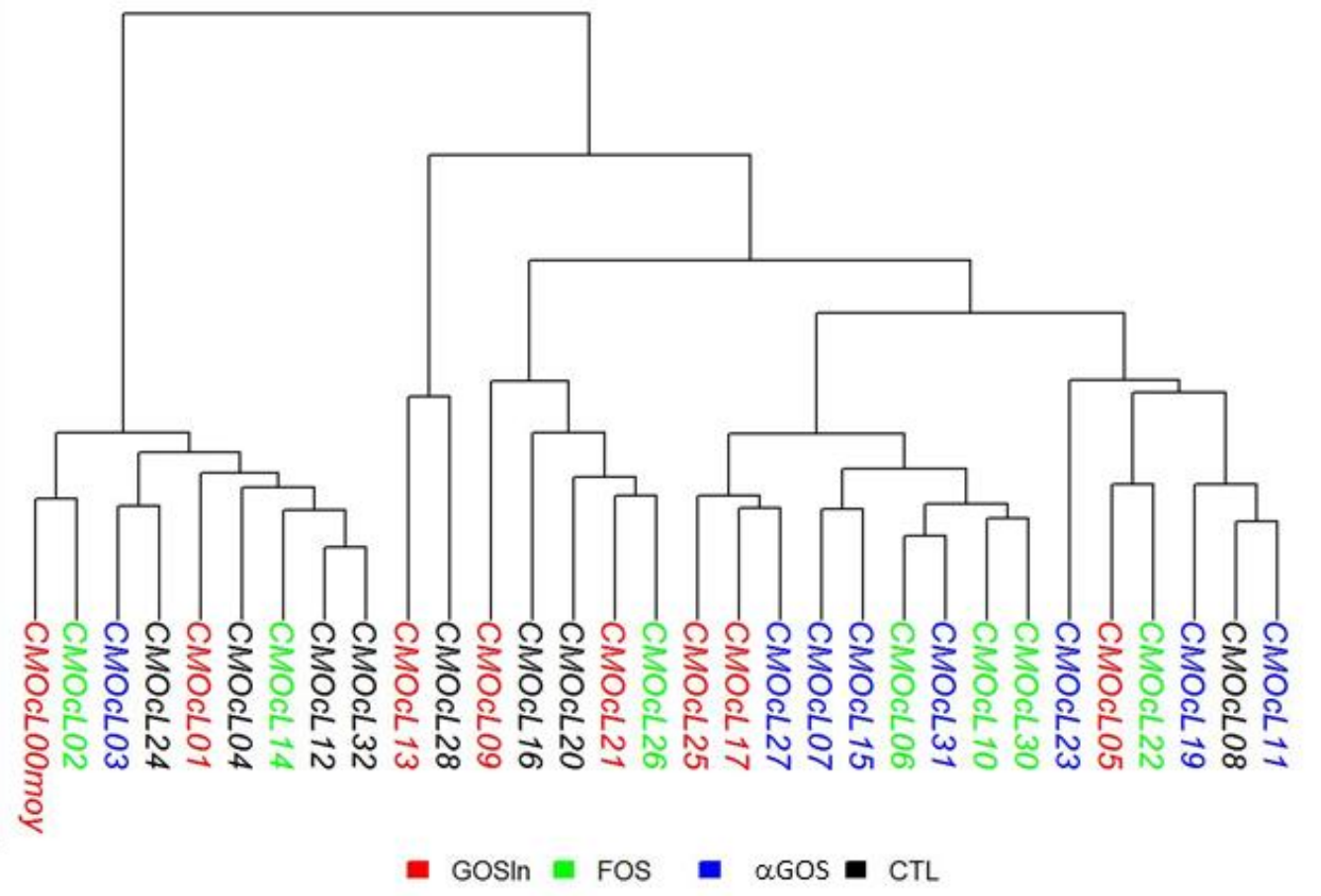

Figure S4. Hierarchical clustering based on the Ward's method of phylogenetically informed distance matrix computed using the unweighted UniFrac metric for cecocolonic contents collected at PND 124/126.

Table S2. Concentration of SCFA in ileal and ceco-colonic contents at PND 124/126

\begin{tabular}{|c|c|c|c|c|c|c|c|}
\hline \multirow[b]{2}{*}{ Treatment } & \multicolumn{3}{|c|}{$\begin{array}{l}\text { Ileal concentrations } \\
\text { (mM) }\end{array}$} & \multicolumn{4}{|c|}{ Ceco-colonic concentrations (mM) } \\
\hline & Acetate & Propionate & Butyrate & Acetate & Propionate & Butyrate & Minors \\
\hline CTL & $2.1 \pm 1.0$ & $0.1 \pm 0.1$ & $N^{1}$ & $13.5 \pm 3.3$ & $3.5 \pm 0.8$ & $2.7 \pm 1.1$ & $1.4 \pm 0.5$ \\
\hline FOS & $2.2 \pm 1.6$ & $0.1 \pm 0.1$ & ND & $11.1 \pm 1.9$ & $2.9 \pm 0.5$ & $2.1 \pm 0.7$ & $1.2 \pm 0.2$ \\
\hline GOS/In & $2.7 \pm 1.5$ & $0.2 \pm 0.2$ & ND & $11.7 \pm 3.1$ & $3.3 \pm 0.9$ & $1.9 \pm 0.7$ & $1.3 \pm 0.5$ \\
\hline$\alpha G O S$ & $2.9 \pm 1.4$ & $0.1 \pm 0.1$ & ND & $10.7 \pm 1.9$ & $2.9 \pm 0.5$ & $1.7 \pm 0.5$ & $1.2 \pm 0.3$ \\
\hline
\end{tabular}

${ }^{1} \mathrm{ND}$, non-detectable. Data are means \pm SD ( $n=7$ to 8 per groups) 